SFB

Why do some insurers become 823 systemically relevant?

Gregor N.F. Weiß, Janina Mühlnickel

Nr. 26/2013
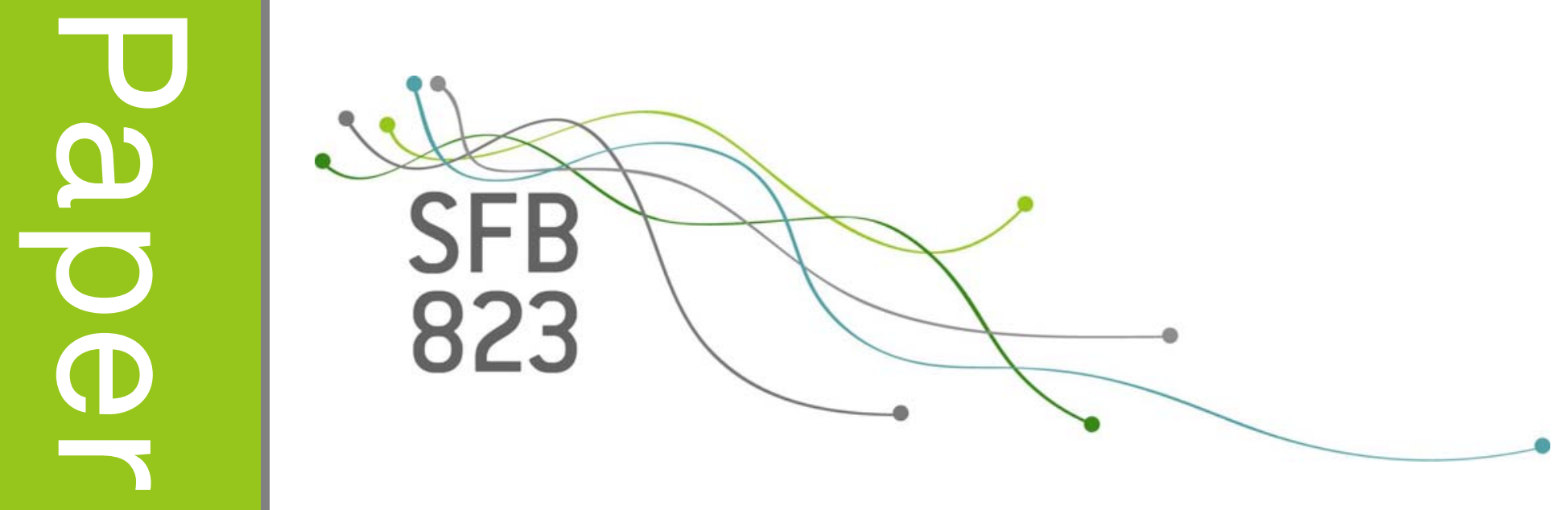



\title{
Why do some insurers become systemically relevant?*
}

\author{
Gregor N.F. Weiß ${ }^{\dagger}$ \\ Technische Universität Dortmund \\ Janina Mühlnickel ${ }^{\text {* }}$ \\ Technische Universität Dortmund
}

June 29, 2013

\begin{abstract}
Are some insurers relevant for the stability of the financial system? And if yes, what firm fundamentals and aspects of insurers' business models cause them to destabilize an entire financial sector? We find that several insurers did indeed contribute significantly to the instability of the U.S. financial sector during the recent financial crisis. We empirically confirm that insurers that were most exposed to systemic risk were larger, relied more heavily on non-policyholder liabilities and had higher ratios of investment income to net revenues on average. Contrary to current conjectures of insurance regulators, we find that the contribution of insurers to systemic risk is only driven by insurer size.
\end{abstract}

Keywords: Financial Crises, Insurance Industry, Systemic Risk.

JEL Classification: G22, G01, G34.

\footnotetext{
${ }^{*}$ We received very useful comments from Thierry Foucault, Alexander Ljungqvist and Steven Ongena. We are grateful to Janet Gabrysch, Sandra Gabrysch and Felix Irresberger for their outstanding research assistance. Support by the Collaborative Research Centers "Statistical Modeling of Nonlinear Dynamic Processes" (SFB 823) and "Economic Risk" (SFB 649) of the German Research Foundation (DFG) is gratefully acknowledged.

${ }^{\dagger}$ Corresponding author: Otto-Hahn-Str. 6a, D-44227 Dortmund, Germany, telephone: +49 231755 4608, e-mail: gregor.weiss@tu-dortmund.de.

‡Otto-Hahn-Str. 6a, D-44227 Dortmund, Germany, telephone: +49 231755 4608, e-mail: janina.muehlnickel@tudortmund.de.
} 
"We kind of lost our way, AIG did, and we got out of the basic insurance business that we know so well [...]."

Edward M. Liddy, CEO, American International Group, October 22, 2008

\section{Introduction}

Are some insurers relevant for the stability of the financial system? And if yes, what firm characteristics make these insurers different from insurers that are not systemically important? The financial crisis of 2007-2009 is widely regarded to have originated in the banking sector and, more specifically, in the market for U.S. subprime mortgages. Since those years, economists and policymakers have devoted considerable effort to the identification of systemically important financial institutions (SIFIs) and the enactment of tougher capital requirements for banks. However, an early peak in the financial crisis was not caused by the default of a bank but rather by the near-collapse of the multinational insurance company American International Group (AIG). In this paper, we investigate whether U.S. insurers (apart from AIG) became systemically important during the recent financial crisis and examine which idiosyncratic factors were the key drivers of systemic risk in insurance. We find that several insurers did indeed contribute significantly to the instability of the U.S. financial sector. Our analysis reveals that insurers that were larger, that relied more heavily on non-policyholder liabilities and that had higher investment income were severely exposed to the adverse effects of the financial crisis. However, the contribution of insurers to systemic risk is found to be only determined on insurer size.

Until the onset of the financial crisis, financial economists questioned the very existence of systemic risks in the insurance industry. In contrast to banks, insurers do not accept customer deposits and thus do not face the risk of a sudden liquidity shortage following a bank run. ${ }^{1}$ Moreover, an "insurance run" in the form of the cancellation of a large number of insurance policies is also highly unlikely because the cancellation of long-term life insurance policies, for example, usually

$1 \quad$ For some recent studies on systemic risk in banking during the subprime crisis see, e.g., IMF (2010); Longstaff (2010); Brunnermeier et al. (2012). 
implies the realization of severe losses, whereas closing a bank account only implies losses on future interest. In addition, insurers must fulfill more rigorous capital requirements than other financial institutions, thus limiting their potential to destabilize the financial system (see Harrington, 2009). Finally, the hierarchical structure of the insurance industry and the reliance on long-term funding are additional factors that can reduce the systemic relevance of insurers.

Contrary to the belief that insurers are not systemically relevant, insurers nevertheless suffered severe losses on their respective stocks during the financial crisis, with the stocks of U.S. non-life insurers performing even more poorly than the stocks of U.S. banks.

— insert Figure 1 1 here -

As seen from the plots of the four different industry indexes in Figure 1, U.S. insurers did not fare significantly better than U.S. banks in 2007-2009. This performance underlines the conjecture that insurers are susceptible to systemic risk in the financial sector. However, the near-collapse of AIG has led academics and regulators to reassess the possibility of insurers themselves becoming systemically important. Recent studies on the potential systemic relevance of insurers unanimously argue that an insurer can pose a risk to the financial system if it becomes too similar to a bank. For example, both the Geneva Association (2010) and the International Association of Insurance Supervisors (IAIS, 2012) argue that some insurers could contribute to the instability of the global financial sector under some circumstances, citing non-core and non-insurance activities as the major drivers of systemic risk in the insurance industry. ${ }^{2}$ Moreover, the recently developed methodology for identifying globally systemically important financial institutions (GSIFIs) by the IAIS additionally cites several idiosyncratic insurer characteristics as possible drivers of systemic risks in insurance. Despite these recent efforts by insurance regulators, however, we know relatively little about the potential of the insurance sector to destabilize the financial sector.

We empirically test hypotheses that insurers could be susceptible and contribute to systemic risk and find strong evidence of a significant exposure to systemic risk across all major U.S. insur-

2 In a similar fashion, Brunnermeier et al. (2012) argue that non-core activities of banks like, e.g., investment banking increased systemic risk in the U.S. prior and during the financial crisis. 
ers in our sample while larger insurers also contributed significantly to systemic fragility. Using a sample of 89 publicly listed U.S. life, non-life and reinsurers, we show that insurers did not only suffer from the externalities caused by the financial crisis, but also contributed to the severity of the crisis. Both effects are statistically and economically significant.To measure an insurer's exposure and contribution to a tail event across the financial sector, we employ the Marginal Expected Shortfall (MES) and $\triangle \mathrm{CoVaR}$ methodology, respectively. Our key result for the MES is that the average insurer in our sample lost $6.5 \%$ on its stocks on those days that the financial sector crashed during the financial crisis from July 2007 to December 2008. This result is not only highly statistically significant but also economically significant, considering the fact that a comparable sample of large U.S. banks analyzed by Acharya et al. (2010) suffered average losses of only $1.63 \%$ on these days. Similarly, insurers had a statistically and economically significant mean $\Delta \mathrm{CoVaR}$ of $-3.7 \%$ during the crisis and thus contributed considerably to the crisis themselves.

Given the knowledge that several insurers did indeed contribute to systemic risk in the U.S. during the financial crisis, we then turn to our second research question: Why did these insurers become systemically relevant for the financial sector? More specifically, we answer the question: Which idiosyncratic factors made these insurers different from other insurers that did not destabilize the financial sector? As candidate determinants of systemic risk, we focus our attention on the factors used in the methodology proposed by the IAIS. In its consultation paper, the IAIS hypothesizes that insurer size is the main determinant of the systemic risk of an insurer. The motivation behind the use of firm size as an indicator of systemic relevance is obvious at first glance and parallels similar arguments brought forward for large banks. The larger an insurer is and the more services it provides, the higher its systemic relevance will be. In cases in which a large insurer defaults, the resulting negative externalities in the form of directly imposed losses on other institutions and doubts about the health of other insurers could then destabilize the entire financial system. ${ }^{3}$ The ensuing fire sales of insurance contracts by the remaining life and non-life insurers, e.g., because of a margin spiral, financial frictions or statutory reserve regulation (see Koijen and Yogo, 2013),

$\overline{3}$ For a more detailed discussion of the too-big-to-fail difficulty in banking, see Mishkin (1999). 
could in turn force asset prices to further plummet, thus intensifying contagion among insurers and other financial institutions. ${ }^{4}$ Consequently, similar to banks, insurers could become too-big-to-fail providing managers with an incentive to take on more risks than is socially optimal. The positive relation between insurer size and systemic risk, however, is no longer as obvious on closer inspection. As an insurer grows, so does its risk pool, improving the insurer's opportunity to diversify. ${ }^{5}$ Despite this factor, the IAIS also identifies global diversification because a possible driving factor of systemic risks in insurance. Empirical evidence by Weiß and Mühlnickel (2012), however, clearly rejects this hypothesis as cross-border mergers are shown to limit rather than increase the contribution of an acquiring insurer to systemic risk. In contrast, diversifying mergers across insurance lines are found to have an increasing effect on the systemic risk of insurers, thus partially supporting the regulators' argument.

Further potential sources of systemic risk in insurance could arise, for example, from the interconnectedness of an insurer with other financial institutions, most notably banks. Although the empirical evidence by Billio et al. (2012) and Chen et al. (2012) is supportive of a one-directional relation between the systemic risks of banks and insurers, systemic risks in insurance still could spill over into other portions of the financial sector via losses incurred in the insurers' asset management. In addition, insurers engaging too heavily in non-core activities as well as derivatives trading could also single-handedly destabilize the financial sector. ${ }^{6}$

Finally, the recent study of Fahlenbrach et al. (2012) documents the finding that the sensitivity of a financial institution to crises and market turmoil is significantly affected by persistence in the institution's risk culture and/or business model. In their work, bank performance during the LTCM

$4 \quad$ Brunnermeier and Pedersen (2009) cite margin (or haircut) spirals and precautionary hoarding behavior as reasons why financial institutions could engage in fire sales. Their theoretical model of a margin spiral is supported by the empirical evidence found by Adrian and Shin (2010).

5 Due to this, the use of insurer size as an indicator of systemic risk in the IAIS methodology was heavily criticized by the Secretary General of the Geneva Association, John Fitzpatrick, who stated: "The insurance business is based on the law of large numbers, that as the number of risks in a portfolio increases the riskiness of the portfolio decreases.[...] Several of the indicators penalise this natural risk reduction rather than reward it."

6 Bartram et al. (2011) show in their empirical study that the use of financial derivatives significantly reduces both total risk and systematic risk of industrial firms. Although the use of derivatives for hedging purposes is usually associated with a decrease in firm risk, excessive derivatives trading by insurers has nevertheless been cited as a major source of systemic risk during the financial crisis (see Cummins and Weiss, 2010). 
crisis in 1998 is revealed to be an economically significant predictor of the performance during the financial crisis. In a related study, Aebi et al. (2012) show that the performance of banks during the financial crisis was driven partially by the quality of the banks' risk governance. A similar view is shared by Diamond and Rajan (2009), who also emphasize that flaws in risk governance contributed to the poor performance of banks during the financial crisis. In theory, these findings should apply to insurers as well. For example, the contribution of an insurer to systemic risk could simply be driven by a persistent risk culture of overly risky underwriting or asset management. In addition, we would expect insurers with more elaborate risk governance to fare better in times of a systemic crisis, which in turn should stabilize the entire financial sector. Until now, however, these hypotheses concerning the drivers of systemic risk in insurance have not been analyzed.

We perform a variety of regressions to explain the cross-sectional variation in both the contribution as well as the exposure of U.S. insurers to system-wide tail events and find that insurers that were significantly exposed to systemic risk were larger and relied more heavily on nonpolicyholder liabilities and on investment income. This result holds after controlling for the higher investment income to net revenues ratio of life insurers and regardless of whether we include reinsurers in our sample. Conversely, the contribution to systemic risk is driven only by insurer size with AIG, Prudential, Metlife and Genworth being major systemically important insurers. The evidence we find poses a substantial challenge to the recently proposed methodology of the IAIS for identifying systemically important insurers. On the one hand, few of the IAIS factors like insurer size and investment activity and success are shown to be valid predictors of an insurer's systemic relevance. On the other hand, we find several of their indicators to be uncorrelated with an insurer's contribution to systemic risk. In particular, substitutability, global activity and the interconnectedness with the reinsurance industry do not predict the systemic relevance of an insurer and thus should not be penalized by the IAIS assessment methodology. Finally, we perform probit regressions in which we predict the membership of insurers in the top quartile of systemic risk exposure as well as the probability of a bailout. Our results confirm that size, non-policyholder liabilities and investment income can be used to identify insurers that are most vulnerable to systemic tail 
events while insurer size predicts the probability of a bailout.

Our paper is related to several recent studies on the financial crisis. The majority of these papers, however, are concerned with the performance of banks and its determinants rather than systemic risk. Beltratti and Stulz (2012) study the performance of a global sample of banks and find that banks with more fragile financing and with better governance performed worse during the financial crisis. Fahlenbrach and Stulz (2011) find that banks with CEOs whose incentives were better aligned with the interests of shareholders performed worse during the crisis. Similarly, Cheng et al. (2010) show that the excess compensation of managers is positively correlated with risk taking, pushing managers towards a risky business model. The performance of banks during the financial crisis is also investigated by Fahlenbrach et al. (2012), who show that banks that performed worse during the LTCM crisis also performed worse during the credit crisis. Our paper is also related to the works of Brunnermeier et al. (2012) and Hovakimian et al. (2012) on the contribution of U.S. banks to systemic risk. Whereas Brunnermeier et al. (2012) show that non-core activities such as investment banking proxied by a high non-interest income are positively related to a bank's $\triangle \mathrm{CoVaR}$ and MES, Hovakimian et al. (2012) find bank size, leverage and asset risk to be the key drivers of systemic risk. In contrast to the aforementioned studies on banks, however, we concentrate our analysis on the potentially significant contribution of insurers to systemic risk.

Turning to the previous insurance literature, our work is related to the analysis in Cummins and Weiss (2010), who hypothesize that non-core activities and high degrees of interconnectedness are the primary causes of insurers' systemic relevance. The potential of the insurance industry to destabilize the financial sector is also confirmed by Billio et al. (2012) who find that the illiquidity of both bank and insurance assets makes these sectors a source of systemic risk. In contrast to these findings, Chen et al. (2012) find in their analysis of credit default swap and intraday stock price data that banks create significant systemic risk for insurers but not vice versa. Although these studies shed some light on the question of whether the interconnectedness of banks and insurers could destabilize the financial sector, they do not answer the question regarding whether insurers actually did contribute to the severity of the financial crisis. Acharya et al. (2009) 
take a first step in this direction by analyzing the contribution of large U.S. insurers to the instability of the financial sector after the collapse of Lehman Brothers. These researchers document the first empirical evidence of a systemic relevance of large insurers but do not perform a crosssectional analysis of the systemic risk contributions that were found. Extending these few studies on systemic risk in insurance, our paper thus constitutes the first analysis of the contribution of U.S. insurers to systemic risk and of the determinants of this destabilizing effect during the credit crisis.

Finally, our paper is also related to the growing body of literature on systemic risk measurement. ${ }^{7}$ Using well-known risk measures from firm-level risk measurement, Acharya et al. (2010) and Adrian and Brunnermeier (2010) propose competing measures for the contribution of an individual financial institution to the stability of the financial sector. Whereas the $\Delta$ CoVaR measure of Adrian and Brunnermeier (2010) is based on the Value-at-Risk (VaR) of a given institution conditional on the financial sector being under distress, Acharya et al. (2010) propose an extension of the $\Delta$ CoVaR called Marginal Expected Shortfall, which is simply defined as the average return on a firm's stock on those days the financial sector experienced its $5 \%$ worst returns. We follow Adrian and Brunnermeier (2010) and argue that $\Delta$ CoVaR can be used to measure an insurer's contribution to a systemic crisis whereas the MES measures the financial institution's exposure to a systemic crisis. ${ }^{8}$ As a robustness check, we control for the fact that both MES and $\triangle \mathrm{CoVaR}$ do not incorporate measures of firm leverage into the assessment of systemic risk and estimate the SRISK measure of Brownlees and Engle (2012) and Acharya et al. (2012) and find that our conclusions remain unchanged.

The remainder of this article is structured as follows. Section 2 introduces the data and the methodology used in our empirical study. Section 3 presents the results of our investigation into the determinants of systemic risk in the U.S. insurance industry. The concluding remarks are given

$7 \quad$ Various other measures of systemic risk have been proposed in the literature following the financial crisis. Further examples for such measures apart from those used in this study are due to De Jonghe (2010); Huang et al. (2011); Schwaab et al. (2011); Hautsch et al. (2012) and White et al. (2012).

8 The fundamental difference between $\triangle \mathrm{CoVaR}$ and MES is that the conditioning has been switched. Note that the MES is closely related to the $\triangle \mathrm{CoVaR}$ measure of Adrian and Brunnermeier (2010) as well as the systemic risk measures by Huang et al. (2011) in which the conditioning has also been switched. 
in Section 4.

\section{Data}

The following section outlines the construction of our sample as well as data sources, defines the main dependent and independent variables used in the statistical analysis and presents descriptive statistics of our data.

\subsection{Sample construction and data sources}

To construct our sample, we select all publicly traded insurance companies with U.S. headquarters, using the country and dead-firm lists in Thomson Reuters Financial Datastream. ${ }^{9}$ To minimize a potential survivorship bias, we also include insurance companies that failed or were delisted during or after our sample period. Financial accounting data are retrieved from Thomson Reuters Worldscope. We chose to retrieve data from Datastream rather than Compustat due to the wider market coverage of firms in the former after 1998 (see, e.g., Ulbricht and Weiner, 2005, for a comparison of both databases) and the availability of some additional data items for insurers. Our initial sample consists of 154 insurance companies, from which we exclude companies for which Datastream does not contain stock prices for the years 2006 to 2008. Also excluded are firms with only incomplete data on the balance-sheet variables that we use (25 insurers). Note that excluding insurers with incomplete data from our analysis could possibly lead to a selection bias in our results because the incompleteness of an insurer's data could be the result of the insurer's opacity. Our sample could thus be biased because (presumably) systemically riskier insurance firms are systematically omitted. ${ }^{10}$ To rule out such a selection bias, for each of the insurance companies omitted from our sample based on either missing stock or balance-sheet data (or both), we manually check

$9 \quad$ Several recent studies by, e.g., Karolyi et al. (2012) and Hou et al. (2011) make similar use of Datastream due to its broad and deep coverage of the global stock market.

10 In a recent study on European banking, Vallascas and Keasey (2012) investigate the relation between systemic risk and bank opacity showing that a bank's transparency contributes to the reduction of its systemic risk potential. 
whether at least one annual report is available from a publicly accessible data source. ${ }^{11}$ For all omitted firms, annual reports thus could be found.

Next, we retrieve additional accounting data and information on the insurers' lines of business and corporate governance from the insurers' 2006 10-K and DEF 14A filings with the SEC. For this purpose, we employ the Morningstar Document Research database. ${ }^{12}$ We then match firms in Datastream/Worldscope and Morningstar by the use of the insurers' ticker symbol (Worldscope data item WC05601) and exclude 23 firms for which Morningstar does not include the insurer's 10-K filing for the year 2006.

The definition of life and non-life insurance companies in the company lists of Datastream is somewhat fuzzy. ${ }^{13}$ Therefore, the industry classification of Datastream is cross-checked with the firms' SIC code (Worldscope data item WC07021, SIC codes 6311, 6321, 6331, 6351, 6361, 6399) and the Industry Classification Benchmark (ICB) code (Worldscope data item WC07040, ICB supersector 8500) to exclude firms that cannot be clearly classified as life or non-life insurance companies. ${ }^{14}$ Additionally, all company names are manually screened for words that might suggest the non-insurance nature of the companies' business, and the respective companies are excluded from the sample. This screening reduces the sample size to 91 firms.

For reasons of relevance, we concentrate on insurance firms with total assets in excess of $\$ 100$ million at the end of 2011. In a related study, Beltratti and Stulz (2012) restrict their sample to banks with total assets in excess of $\$ 10$ billion. Their analysis, however, focuses on the crosssectional determinants of the performance of already systemically relevant banks during the recent financial crisis. ${ }^{15}$ Because our study is concerned with the determinants of the systemic relevance (or irrelevance) of insurers, however, a too-strict size requirement would prevent a cross-sectional analysis of the effects of insurer size on systemic relevance. This size requirement leads to the

11 Usually, annual reports could be found on the respective company's webpage.

12 Morningstar Document Research (10k Wizard) offers the user the ability to access Form 10-K and 10-Q filings of U.S. firms online.

13 For example, several medical service plans and medical wholesale companies are listed as life insurance companies in Datastream's company lists.

14 Consequently, HMOs and managed care insurance companies are not included in the final sample.

15 The $\$ 10$ billion-size threshold is derived by the threshold of $\$ 50$ billion total assets postulated in the Dodd-Frank Act. 
exclusion of one insurer.

Next, to control for known data errors in Datastream, we apply several screening procedures for the daily returns on the insurers' stock prices. We follow Ince and Porter (2006) and first exclude from our sample the days in which the stock price of the respective insurer drops at least once below a minimum price of $\$ 1$ to control for a bias induced by the practice in Datastream of rounding prices. Second, we check our sample for insurers with at least one monthly return above $300 \%$ that is reversed in the following month. ${ }^{16}$ We find that none of the remaining insurers in our sample suffers from such erroneous stock prices. ${ }^{17}$ Third, we manually check the data for other non-trivial data errors and anomalies, which leads to the exclusion of Berkshire Hathaway from our sample because of its unusually high stock price. Finally, we identify non-trading days as those days on which the ten largest companies in our sample (with respect to their market capitalization) exhibit a stock return equal to zero. Days which contain more than $80 \%$ zero returns across our sample are treated as "missing". Our final sample thus consists of 89 U.S. insurance firms. For increased transparency, all insurers in our final sample are listed in Appendix I. To ensure that our sample and the coverage in Datastream are representative of the U.S. insurance industry, we first check whether our sample includes the constituents of selected insurance sector indices. As an example, we check whether the firms listed in the $K B W$ Insurance Index $(K I X)$ are included in our sample, finding a broad coverage of the $K I X$ (20 out of 24 companies in our final sample, with all 24 firms listed in the $K I X$ entering our initial sample). Furthermore, we compute the total market capitalization of the insurers in our sample ( $\$ 726$ billion) and compare the results with the statistics on the market capitalization of the U.S. insurance industry in the Yahoo Finance Industry Browser. The results show that our sample is sufficiently representative of the U.S. insurance industry.

16 More precisely, given two monthly returns $R_{t}$ and $R_{t-1}$, we check if either $R_{t}$ or $R_{t-1}$ is greater than 300\%, and $\left(1+R_{t}\right) \cdot\left(1+R_{t-1}\right)-1<50 \%$. Although the $300 \%$ threshold is somewhat arbitrary, Ince and Porter (2006) show that this threshold appears to perform well for minimizing differences between returns calculated from stock prices taken from Datastream and the Center for Research in Security Prices (CRSP) databases.

17 We also reestimate our analyses using stock price data from CRSP instead of data from Datastream as a further robustness check. Our results remain unchanged. 


\subsection{Measures of systemic risk}

Our analysis focuses on the exposure and contribution of individual insurers to the systemic risk of the U.S. financial sector during the period July 1, 2007 through December 31, 2008. We follow Beltratti and Stulz (2012) and Fahlenbrach et al. (2012) and consider this period as the climax of the financial crisis to keep our study comparable to their work on bank performance. However, one could propose different definitions of the critical time frame of the credit crisis because both banks and insurers continued to report severe losses well into 2009. We control for the possibly confounding effect of our particular choice of the time frame by re-estimating our models of systemic risk for the time period ending December 31, 2009 as well as for the recession dates given by the NBER (December 2007 to June 2009) in our robustness checks. As our main dependent variables, we use each insurer's $\triangle \mathrm{CoVaR}$ (see Adrian and Brunnermeier, 2010) and static MES (see Acharya et al., 2010) during the climax of the crisis to proxy for the respective insurer's contribution and exposure to systemic risk, respectively. ${ }^{18}$ The MES measure we use is criticized by Adrian and Brunnermeier (2010) in their work on the $\Delta \mathrm{CoVaR}$ measure of systemic risk for not addressing the procyclicality stemming from contemporaneous risk measurement and for measuring the exposure of a financial institution and not its contribution to systemic risk. Conversely, Acharya et al. (2010) emphasize that MES should be preferred to $\triangle \mathrm{CoVaR}$ due to the former being based on a coherent risk measure. To address both concerns, both measures of systemic relevance are used in our study.

Adrian and Brunnermeier (2010) define an institution's CoVaR as the Value-at-Risk (VaR) of the financial system conditional on institutions being under distress. An insurer's contribution to system risk is then measured as the difference between CoVaR conditional on the insurer being under distress and the CoVaR in the median state of the institution. We follow Adrian and Brunnermeier (2010) and estimate an insurer's conditional $\Delta$ CoVaR by using the change in the three-month Treasury bill rate, the difference between the ten-year Treasury Bond

$18 \quad$ A theoretical and empirical comparison of both MES and $\triangle$ CoVaR is given by Benoit et al. (2013) who show that while $\triangle \mathrm{CoVaR}$ is the method of choice for ranking systemically important institutions, MES should be used for forecasting the contribution of a particular institution to the global risk of the financial system. 
and the three-month Treasury bill rate, the change in the credit spread between BAA-rated bonds and the Treasury bill rate, the return on the Case-Shiller Home Price Index, and implied equity market volatility from VIX as state variables.

Conversely, the MES of an individual insurer is defined as the negative mean of the log returns on the insurer's stocks, conditional on the financial sector experiencing its worst $5 \%$ outcomes. ${ }^{1920}$ To proxy for the market return of the financial sector, we use the S\&P 500 Financials Sector Index. The estimation of the static MES is based on very few observations in the extreme tail of the joint distribution of an insurer's and the market's returns. To control for the possibility that our results are driven by a few outliers in the data (most notably the near-collapse of AIG and the default of Lehman Brothers), we also use average MES estimates from the dynamic model of Brownlees and Engle (2012). In their model, the joint behavior of the market and firm returns is characterized by both time varying volatility and correlation, which are modeled with the TARCH (see Rabemananjara and Zakoïan, 1993) and DCC (see Engle, 2002) specifications. We use this dynamic model to compute daily MES estimates for all trading days in the crisis period and employ the average of these daily MES estimates in our robustness checks.

Finally, both MES and $\triangle \mathrm{CoVaR}$ could be criticized for not taking into account the leverage of a financial institution. As a remedy, Acharya et al. (2012) and Brownlees and Engle (2012) propose a Systemic Risk Index (SRISK) to measure the expected capital shortfall of a firm in a crisis. The SRISK estimate for firm $i$ at time $t$ is given by

$$
S \operatorname{RISK}_{i, t}=k\left(\operatorname{Debt}_{i, t}\right)-(1-k)\left(1-\text { LRMES }_{i, t}\right) \text { Equity }_{i, t}
$$

where $k$ is a regulatory capital ratio (set to $8 \%$ ), Debt $_{i, t}$ is the firm's book value of debt, $L R M E S_{i, t}$ is the long run Marginal Expected Shortfall defined as $1-\exp (-18 \cdot d y n M E S)$, dynMES is the dynamically estimated MES and Equity ${ }_{i, t}$ is the firm's market value of equity. In our study, we

$19 \quad$ A positive MES thus indicates a contribution to systemic risk rather than a stabilizing effect.

20 Note that Acharya et al. (2010) derive their MES measure by dividing the so-called Systemic Expected Shortfall (i.e., a financial institution's capital shortage in the event of a systemic crisis) by the firm's equity. By definition, the MES should thus (approximately) be scaled by firm size. 
additionally employ SRISK as a further measure of systemic relevance in our robustness checks.

\subsection{Key IAIS indicators of systemic relevance}

Using the measures mentioned above, we investigate the hypothesis that the extent to which insurers contributed to the instability of the U.S. financial sector during the crisis can be explained by the idiosyncratic characteristics of insurers in the year before the start of the crisis. We test this hypothesis through the use of two sets of idiosyncratic variables. All variables used in our study are defined in Appendix $\amalg$.

The first set of independent variables includes several key items in the recently proposed methodology of the IAIS for identifying systemically relevant insurers. Our particular choice of variables in this second set is partially dictated by the availability of the data. The methodology proposed by the IAIS has been devised for regulators for the use on publicly and non-publicly available data. Unfortunately, the latter is not available to us. We attempt to alleviate this limitation and complement the variables taken from Worldscope by using variables extracted from manually evaluating each insurer's 10-K filing with the SEC for 2006.

As a first indicator of systemic relevance, we use the logarithm of an insurer's total assets to proxy for firm size. We expect the sign of the coefficient of total assets to be unrestricted in our regressions. On the one hand, total assets could be positively correlated with an insurer's contribution and exposure to systemic risk, because larger insurance companies have a wider range of different risks insured and thus are less prone to suffer from cumulative losses (see Hagendorff et al., 2011). At the same time, larger insurance companies could become too-interconnected-to-fail and thus systemically relevant (see Acharya et al., 2009). The IAIS shares this latter argument and proposes insurer size to be a key determinant of an insurer's ability to destabilize the financial sector.

Next, we use the variable Net revenues, defined as the total operating revenue of an insurer in 2006. The IAIS uses the revenues of an insurer as an additional proxy for insurer size, arguing that larger insurers are automatically more systemically relevant. Consequently, we employ Net 
revenues as an alternative to Total assets in our robustness checks. Next, the IAIS follows the argumentation presented by Cummins and Weiss (2010) and Brunnermeier et al. (2012) that noncore activities of financial institutions were the major drivers of systemic risk before the subprime crisis. To capture an insurer's activities outside of the classical insurance business, we thus use the variable Non-policyholder liabilities, which is defined as the total of balance sheet liabilities minus total insurance reserves (including benefit and loss reserves, unearned premiums, policy and contract claims and other reserves). To further proxy for the non-core activities of an insurer, in our regressions we employ the variable Other income, defined as the residual of total income minus operating income, non-operating interest income, interest expense on debt and interest capitalized. Closely related to non-core activities, the systemic relevance of an insurer could be related to an insurer's investment activity. For example, life insurers that predominantly derive their revenues from asset management rather than underwriting could be more intertwined with global financial markets and could thus contribute more to systemic risk than other insurers. Therefore, we define the variable Investment success as the ratio of an insurer's investment income to net revenues to proxy for the success of the insurer's asset management. Furthermore, we employ the variable Investment activity defined as the absolute value of investment income divided by the sum of the absolute values of investment income and earned premiums to proxy for the degree with which the insurer derives its income from investing assets rather than earning premiums from underwriting. To control for the fact that life insurers regularly have higher investment income to net revenues ratios, in our regressions we also employ a dummy variable called Life insurer, which takes on the value one for life insurers and zero otherwise.

The contribution of an insurer to systemic risk could also depend on the extent of the insurer's global activity. To measure global activity, the IAIS proposes using the number of countries in which a group operates with branches and/or subsidiaries outside of the home country. We adopt this IAIS proposal and employ the variable Global activity, which is defined as the number of countries in which an insurer operates a sales office and/or subsidiary including the home country. We retrieve the data from Morningstar on Global activity by searching the 2006 10-K filing of 
each insurer for information on subsidiaries and countries in which the insurer has a business operation. ${ }^{21}$ To proxy for the interconnectedness of an insurer with the reinsurance industry, we use the variables Assumed reinsurance and Ceded reinsurance to describe the ratio of written premiums ceded to reinsurance to total written premiums and the ratio of assumed reinsurance premiums to total written premiums, respectively. We expect higher values for both variables to indicate a higher degree of interconnectedness with the reinsurance business and therefore a higher contribution to systemic risk. Finally, the IAIS also hypothesizes that unique services of an insurer could increase the institution's systemic relevance because its services could not be substituted by other competitors in case of a default. Ideally, we would like to measure an insurer's substitutability by using the direct gross premiums written in certain specialty lines of insurance (e.g., credit coverage, guarantee coverage and financial guarantee coverage). However, not all insurers in our sample report premiums written in a differentiated manner by insurance lines in their 10-K filings. We therefore construct a score value Substitutability that captures the number of lines of specialty insurance in which an insurer operates. ${ }^{22}$

\subsection{Insurer characteristics}

The second set of variables covers standard firm characteristics taken from insurer balance sheets and income statements and computed from stock returns. The data are taken from the Thomson Worldscope database. We employ an insurer's leverage ratio as an independent variable in our regressions. We follow Acharya et al. (2010) and Fahlenbrach et al. (2012) and approximate an insurer's leverage as the quasi-market value of assets divided by the market value of equity in which the quasi-market value of assets is given by the book value of assets minus the book value of equity plus the market value of equity. We expect the sign of the coefficient of leverage to be unrestricted. For example, Vallascas and Hagendorff (2011) argue that managers

21 We double check our data with the information given on each insurer's website on its global sales offices as of 2012 , confirming the reliability of the data from the 10-K filings.

22 In contrast to the values of the premiums written, all 10-K filings report the lines of business in which the insurer operates so that we are able to construct our variable Substitutability for all firms in our sample. 
of highly levered companies could come under pressure from investors to provide enough liquid assets to cover the payments of interest, which in turn could decrease the insurer's total risk. On the other hand, managers could also be inclined to excessively take on risks because leverage forces managers to increase firm profitability. This view is supported by the empirical evidence by Acharya et al. (2010), Fahlenbrach et al. (2012) and Hovakimian et al. (2012), who find that banks with low leverage performed better and contributed less to systemic risk during the crisis. Furthermore, in our regressions we use an insurer's market-to-book ratio, defined as the book value of common equity divided by the market value of common equity. We expect a negative relation between the market-to-book ratio and the systemic risk because the overvaluation of an insurer before the crisis could have indicated high growth expectations on the part of the investors. In turn, overstated growth expectations could have led to excessive risk-taking by managers (see, e.g., Milidonis and Stathopoulos, 2011).

The next variable we consider is a measure of an insurer's debt maturity. There exists a wide consensus among economists and regulators that the dependence of certain banks and insurers on short-term funding exposed these institutions to liquidity risks during the financial crisis and ultimately led to significant systemic risks (see Brunnermeier and Pedersen, 2009; Cummins and Weiss, 2010; Fahlenbrach et al., 2012). Consequently, the IAIS has included the ratio of the absolute sum of short-term borrowing and total assets in its methodology as a key indicator of systemic relevance. We adopt their line of thought but follow Fahlenbrach et al. (2012) by using short-term debt relative to total debt rather than total assets as a proxy for short-term funding. We also use Fixed income, which is defined as the ratio of the value of fixed income securities investment to total investment to characterize an insurer's asset portfolio. Insurers in which Fixed income is higher are insurers with a more conservative asset portfolio before the crisis. If insurers had invested more strongly in other asset classes (e.g., stocks) rather than fixed income products, we would expect these insurers to have suffered more profoundly from plummeting asset prices during the crisis, forcing them to engage in fire sales themselves. A more conservative asset portfolio should thus be negatively related to an insurer's contribution to systemic risk. To further 
characterize the quality of an insurer's asset portfolio, we also use the variable Asset quality, which is defined as the ratio of the value of bonds below investment grade and total investments. Again, we expect a higher asset portfolio quality to be negatively related to an insurer's contribution to systemic risk because the insurer was less likely to engage in fire sales. We also use the variable Liquidity beta, which is defined as the regression liquidity beta of an insurer's excess return on the market-wide liquidity innovations, as proposed by Pástor and Stambaugh (2003) for the years 2004 to 2006 to proxy for an insurer's exposure to illiquid assets. If insurers held more liquid assets, they could have been in a better position to reduce their balance sheet and to avoid financial distress. However, insurers with more liquid assets could also have been the ones that were more likely to liquidate assets even during times of market turmoil. Therefore, we have no prediction for the relation between Liquidity beta and an insurer's contribution to systemic risk. To characterize the quality of the insurance portfolio, in our cross-sectional analyses we employ an insurer's Loss ratio, defined as the claim and loss expense plus long-term insurance reserves divided by premiums earned, expecting insurers with higher loss ratios to contribute more to systemic risk.

To proxy for an insurer's profitability, we employ the insurer's return on assets at the end of 2006 and the variable Income variability, defined as the standard deviation of the insurer's return on assets during the years 2004 to 2006 . Our prediction is that higher profitability is related to decreases in an insurer's contribution to systemic risk because more profitable insurers also have higher solvency margins and a lower risk of insolvency (see also De Haan and Kakes, 2007). Income variability, on the other hand, is expected to be positively related to our measures of systemic risk because more volatile profits could be indicative of an elevated level of risk-taking by the insurer. The contribution of an insurer to the systemic risk of the entire financial sector could also be driven by the insurer's risk culture. Following Fahlenbrach et al. (2012), we also use the buyand-hold returns of an insurer during the LTCM crisis in 1998 as a proxy for a more risk-friendly culture of underwriting risks in our regressions. Next in our regressions, we also use the insurers' operating efficiency, given by the ratio of operating expenses to total assets, to control for the quality of management. 
Finally, Diamond and Rajan (2009) and Aebi et al. (2012) emphasize that poor governance contributed to the severity of losses that banks suffered during the financial crisis. ${ }^{23}$ We therefore use the variables Board size and Board independence to proxy for the governance of insurers before the financial crisis. Board size is defined as the natural logarithm of the number of directors on an insurer's board. We expect board size to be positively related to systemic risk because larger boards have been found to destroy firm value and possibly capital buffers (see Yermack, 1996). To proxy for the independence of the board, we use the percentage of independent outside directors on the board of directors. Because outside directors should be more concerned about the systemic risk of the financial sector as a whole, we expect Board independence to have a decreasing impact on the systemic risk of an insurer.

\subsection{Descriptive statistics}

Table Ipresents summary statistics for our systemic risk measures and independent variables.

$$
\text { — insert Table \here - }
$$

The median and mean MES for our sample of U.S. insurers in the period between July 2007 and December 2008 are 5.91\% and 6.5\%, respectively. In addition to AIG, five insurers in our sample received aid under the Troubled Asset Relief Program (TARP). All of these bailed-out insurers are in the top MES quartile and have a significantly higher median and mean MES of $11.9 \%$ and $11.5 \%$, respectively. The daily estimates of the MES, computed from the dynamic model of Brownlees and Engle (2012), are averaged across our full sample period. The resulting averages are comparable to the static MES estimates, with a median and mean dynamic MES of $5.8 \%$ and $6.9 \%$, respectively. The daily MES estimates offer an insight into the temporal evolution of systemic risk exposure in insurance during the financial crisis. Figure 2 plots the average daily MES estimates (solid line) together with the MES estimates between the 5\% and 95\% quantiles (shaded area).

23 However, Beltratti and Stulz (2012) find empirical evidence for the opposite argument that good governance might have been indicative of banks taking on too many risks before the crisis. 
— insert Figure 2 here -

The dynamic MES estimates illustrate the extreme increase in the average exposure of U.S. insurers to systemic fragility around and after the collapses of AIG and Lehman Brothers. While average daily MES estimates were already at an elevated level of 3\% to 5\% at the start of 2008, the months following the default of Lehman were characterized by even higher exposure to systemic risk, with average MES estimates of insurers reaching 27\%. Estimates for our measure of an insurer's contribution to systemic risk, $\Delta \mathrm{CoVaR}$, show that the average U.S. insurer was not only significantly exposed to systemic risk, but also had a significant impact on financial fragility during the financial crisis, with a mean $\triangle \mathrm{CoVaR}$ of $-3.7 \%$ in our full sample. To further analyze the relation between an insurer's exposure to systemic risk on the one hand, and its own contribution to systemic fragility on the other hand, Figure 3 presents a scatter plot of the average dynamic MES estimates against the estimates for $\triangle \mathrm{CoVaR}$.

— insert Figure 3 here -

We can see from the plot in Figure 3 that an insurer's contribution and exposure to systemic risk seem to be positively correlated. ${ }^{24}$ Although not an indication of a causal relation, the correlation of $-34 \%$ between the two systemic risk measures nevertheless hints at the possibility that insurers that suffered from market crashes also contributed themselves to systemic fragility (and vice versa). On the other hand, the moderately high correlation between MES and $\triangle \mathrm{CoVaR}$ indicates that both measures are capturing different angles of systemic risk.

Turning to our explanatory variables, insurers in our sample held only negligible amounts of speculative grade investments prior to the crisis. The mean value of our variable Asset quality is $3 \%$. The median board size is ten, with boards having $81 \%$ independent members on average. The average insurer has $82 \%$ of its assets invested in fixed income products and a mean leverage of 4.59. Because the mean loss ratio of the insurers in our sample is heavily influenced by two outliers, we concentrate on interpreting its median value. The median loss ratio of $64 \%$ is in the typical range

$24 \quad$ Strictly speaking, MES and $\triangle \mathrm{CoVaR}$ are negatively correlated. However, negative values of $\Delta \mathrm{CoVaR}$ signify a positive contribution to systemic fragility. 
for a sample consisting mainly of non-life insurers. The mean market-to-book ratio of insurers is 1.61 and the sub-sample of insurers with stock price data available during the LTCM crisis shows an average stock performance of $-31 \%$ in 1998 . The majority of our sample insurers relied only slightly on short-term funding, with the median and mean values of our variable short-term funding at $0 \%$ and $12 \%$, respectively.

Regarding the indicators of systemic risk as proposed by the IAIS, the average insurer in our sample had total assets of $\$ 45.03$ billion at the end of fiscal year 2006, whereas the median total assets were significantly lower at only $\$ 7.26$ billion. An average insurer also assumed and ceded only up to $20 \%$ of its total written premiums to reinsurance. The majority of insurers are active in the U.S. only with no subsidiaries in foreign countries. Several large insurers, however, have large numbers of subsidiaries around the globe, with AIG being the most globally active insurer (86 countries). Similarly, the median insurer is active in only one line of specialty insurance. U.S. insurers are rather heterogeneous with respect to their activity and success in asset management. Ratios of investment income to net revenues range from $-27 \%$ to $57 \%$ across our full sample and have a mean value of zero. Values for our variable Investment activity range from zero to $96 \%$ with the mean ratio of absolute investment income to total revenues being $20 \%$. Similarly, the ratio of the total of balance sheet liabilities minus total insurance reserves to total liabilities, proxying for Non-policyholder liabilities, ranges from $-72 \%$ to $92 \%$ with median and mean ratios of $22 \%$ and $26 \%$, respectively.

\section{Why do some insurers become systemically relevant?}

In this section, we explore the factors that caused some U.S. insurers to be more susceptible to turmoil in the financial system than others. Additionally, we address the question why some insurers became systemically important by significantly contributing to systemic risk during the financial crisis. We begin our analysis by comparing the characteristics of insurers that were most exposed to systemic risk (top MES quartile) and those that had the smallest systemic risk exposure 
(bottom MES quartile). After repeating this exercise for an insurer's contribution to systemic risk $(\triangle \mathrm{CoVaR})$, we then complement these univariate analyses by performing a set of multiple regressions of both systemic risk measures.

\subsection{Characteristics of systemically relevant insurers}

For a first impression of the key drivers of an insurer's systemic risk exposure, we divide our sample of insurers into the top and bottom contributors to systemic risk based on their MES estimates. Table I presents a comparison of several descriptive statistics for our dependent and independent variables for all insurers in the top and bottom MES quartiles. Because a higher value of the MES indicates a higher exposure to systemic risk, the top quartile contains the group of insurers that are more susceptible to market crashes than those in the bottom quartile.

- insert Table $\coprod$ here -

As expected, we observe a large difference in MES between the two quartiles. The mean MES of insurers in the bottom quartile was approximately $3 \%$ over our sample period, whereas insurers in the top quartile had an average MES of $12 \%$. The results for the dynamic MES estimates are similar. Insurers in the bottom quartile had a mean dynamic MES of approximately $3 \%$, with the average dynamic MES in the top quartile of $14 \%$. The results of our third measure of systemic risk, $\triangle \mathrm{CoVaR}$, show a similar picture. Insurers that were systemically relevant according to the MES estimates were also the ones that contributed the most to systemic risk according to their $\Delta \mathrm{CoVaR}$ estimates.

The results presented in Table $\amalg$ show that a lower-quality asset portfolio led to a higher systemic risk exposure for insurers during the crisis. Interestingly, the variability in an insurer's total income appears to be negatively related to the insurer's exposure to systemic risk. Insurers in the bottom MES quartile had an average income variability of 3.24. In contrast, the average value of insurers in the top MES quartile was only 1.22. A possible explanation for this finding could be that higher income variability was related to better growth opportunities and consequently higher 
profits for insurers. ${ }^{25}$ The significantly higher average return on assets of insurers in the bottom quartile corroborates this hypothesis.

Insurers that were more exposed to systemic-wide crashes had significantly more leverage on average, with a mean leverage of 2.87 in the bottom MES quartile and 7.32 in the top quartile. This finding is in line with the argument stated by Brunnermeier (2009), who argue that more leveraged institutions could have been more prone to suffer from loss spirals during the credit crisis. The results for the Loss ratio of the two groups of insurers are heavily influenced by one outlier in the top quartile. The result of the Mann-Whitney test on the difference in the median MES, however, confirms that insurers with a higher exposure to systemic risk also had higher loss ratios. Surprisingly, we do not find that an insurer's exposure to illiquid assets, its performance during the LTCM crisis, the market-to-book-ratio or the level of short-term debt significantly differed between the two groups during the financial crisis. Additionally, there is no statistically significant difference in the number of directors on the insurer's board or the percentage of independent outside directors between the two quartiles. We also find no evidence that insurers that were more exposed to systemic risk had invested more in fixed income securities before the crisis.

Regarding the key indicators of systemic risk proposed by the IAIS, we find that insurers in the top MES quartile have significantly higher net revenues and total assets. Insurers in the top quartile had mean total assets of $\$ 116.24$ billion, whereas insurers in the bottom MES quartile were significantly smaller with average total assets of $\$ 4.02$ billion. The insurers that were most vulnerable to market crashes also had significantly higher investment income to net revenues ratios. In addition, insurers in the top MES quartile had $38 \%$ non-policyholder liabilities on average, whereas the insurers that were less vulnerable to the instability of the financial sector owed only $22 \%$ of their total liabilities to non-policyholders. Furthermore, the insurers that suffered the highest losses on their equity conditional on the U.S. financial sector were more globally active and assumed less reinsurance than their counterparts. Finally, the mean values for an insurer's premiums ceded to

$25 \quad$ A similar reasoning underlies the empirical investigation of Bartram et al. (2012) into the question why U.S. stocks are more volatile than the stocks of similar foreign firms. They find that firm stock volatility is positively related, e.g., to better investor protection, stock market development and firm-level investment in R\&D 
reinsurance and its level of substitutability did not differ significantly between the two groups. To further underline the findings of our univariate analysis, we plot the insurers' MES against the insurers' total assets in Figure 4 and against their investment income to net revenues ratios in Figure 5 .

- insert Figures 4 and 5 here -

Both plots document a particularly strong positive relation between an insurer's systemic risk exposure and its size and investment success.

In the next part of our analysis, we check whether we can find equally strong correlations between our explanatory variables and an insurer's contribution to systemic risk. To this end, we split our sample into quartiles based on an insurer's $\Delta \mathrm{CoVaR}$ during the financial crisis and compare descriptive statistics for the explanatory variables for insurers in the bottom (insurers which contributed the most to financial instability) and top $\Delta \mathrm{CoVaR}$ quartile.

$$
\text { - insert Table 【here - }
$$

The results of this analysis are reported in Table III. Again, differences between the mean and median $\triangle \mathrm{CoVaR}$ estimates in both quartiles are large by construction. More interestingly, insurers that contributed the most to systemic fragility were also characterized by significantly higher MES (and dynamic MES) estimates and thus a higher exposure to systemic risk. Turning to the differences in our independent variables, the results in Table III show a clear picture. In this univariate setting, an insurer's contribution to systemic risk seems to be driven only by our two proxies for insurer size (total assets and net revenues) and its use of reinsurance. Larger insurers and insurers that assumed (or ceded) less premiums from (to) reinsurers had a higher contribution to the overall systemic risk of the U.S. financial sector. Differences for the remaining explanatory variables between the top and bottom $\Delta \mathrm{CoVaR}$ quartiles are statistically insignificant. 


\subsection{Multiple regressions}

The results of our univariate analysis emphasize that the insurers that were more exposed to systemic risk were larger, relied more strongly on non-policyholder liabilities and had a higher investment income to net revenues ratio, a higher loss ratio, more leverage, and a lower quality of asset portfolio. At the same time, insurers appear to contribute to financial fragility if they become too large or engage less in reinsurance. In this portion of our analysis, we check whether these results hold when employing these predictors of an insurer's exposure and contribution to systemic risk in multiple regressions. Correlations between our independent variables together with p-values are presented in Appendix 【II] The majority of the pairs of independent variables do not exhibit strong correlations. However, some variables are strongly correlated with each other preventing their simultaneous use in regressions.

In our baseline regressions, our dependent variables are an insurer's MES and $\triangle \mathrm{CoVaR}$, respectively. Because our dependent variables result from a first-stage estimation, our regressions will likely suffer from heteroskedasticity (see Lewis and Linzer, 2005). To control for this source of heteroskedasticity (and autocorrelation) in the residuals, Newey and West (1987) standard errors are used. The results of our regressions are presented in Table IV.

$$
\text { - insert Table IV here - }
$$

Model (1) in Table IV presents a regression of the insurers' MES on firm characteristics before the financial crisis using our full sample of insurers. We do not report the estimates of the intercept in our regressions models. Our variables Investment success and Investment activity are highly correlated and consequently, we only employ Investment success in our regressions. Total assets have a positive significant coefficient, as do Investment success and Non-policyholder liabilities ratios, with all three coefficients being highly statistically significant. All three indicators from the IAIS methodology, however, are also highly economically significant predictors of an insurer's contribution to systemic risk. For example, a one-standard-deviation increase in (log) Total assets is associated with an increase in an insurer's MES of 1.99 percentage points $(0.010 \mathrm{x}$ 
1.993). One-standard-deviation increases in the ratio of an insurer's investment income to its total income and its non-policyholder liabilities are associated with an increase in MES of 0.62 (0.046 x 0.135$)$ and 0.69 percentage point $(0.030$ x 0.229$)$, respectively. All other indicators of systemic risk from the proposed methodology of the IAIS do not enter regression (1) with a significant coefficient. Most prominently, our proxies for the level of short-term funding, the global activity and the substitutability of an insurer have no predictive power for its exposure to system risk in the U.S. financial sector. Complementing our previous finding in the univariate analysis, none of our corporate governance variables has predictive power for an insurer's systemic risk exposure.

Regression (2) is the same as our baseline regression (1), except that we now add an insurer's leverage as a further explanatory variable. Due to multicollinearity, Total assets and Investment success are left out from this model specification. Non-policyholder liabilities again enter our regression with a both statistically and economically significant coefficient. A one-standarddeviation increase in Non-policyholder liabilities is associated with an increase of $0.44(0.033 \mathrm{x}$ 0.135 ) percentage point in MES. Leverage is both statistically and economically highly significant in this specification as well. An increase in leverage by one standard deviation is associated with an increase in an insurer's exposure to systemic fragility of 1.39 percentage points $(0.004 \times 3.47)$. Board size is weakly statistically significant in this model and carries a positive coefficient.

In model (3), we add an insurer's loss ratio to our baseline regression leaving out Asset quality and Investment success again due to multicollinearity. Surprisingly, Loss ratio does not enter this regression with a significant coefficient. Insurer size remains a highly significant predictor of an insurer's exposure to systemic risk. Non-policyholder liabilities do not enter regression (3) with a statistically significant coefficient, the magnitude of its economic significance is nevertheless still large. Firm valuation in form of an insurer's market-to-book ratio enters the regression statistically significantly with the expected negative sign.

Regression (4) is the same as our baseline regression (1), except that we now add the liquidity beta and the returns during the LTCM crisis to our model. The requirement of having data on both variables decreases our sample size to 64 insurers. Asset quality now enters our regression with a 
(statistically and economically) significant negative coefficient. Higher returns during the LTCM crisis are associated with a lower exposure to systemic risk during the subprime crisis. This effect is economically significant, with a one-standard-deviation increase in returns during the LTCM crisis decreasing an insurer's MES during the recent financial crisis by $0.89(-0.042 \times 0.213)$ percentage point. Otherwise, the results are similar to those in regression (1). Total assets, Investment success and Non-policyholder liabilities are both statistically and economically significant drivers of an insurer's exposure to financial fragility.

Regarding the significance of our variable Investment success, the results stress the importance of market price risks originating in an insurer's asset management for its systemic relevance. However, one could argue that our results are simply driven by the fact that our sample includes both life and non-life insurers because life insurers, on average, earn a significantly larger portion of their income from investing in capital markets than comparable non-life insurers. To check whether our main results hold for both life and non-life insurers, we repeat regression (1) for the sub-samples of non-life insurers in regression (5). Insurer size remains a statistically and economically significant driver of a non-life insurer's exposure to systemic risk, although the variable's significance loses in magnitude. The investment income to net revenues ratio enters regression (5) with a statistically significant positive coefficient. Surprisingly, the economic significance of our variable Investment success is considerably larger than in regression (1) as a one-standard-deviation increase in Investment success increases a non-life insurer's MES by 2.16 percentage points $(0.161$ x 0.134$)$. A more pronounced financing via non-policyholder liabilities is no longer a significant driver of systemic risk exposure. Global activity enters our regression statistically significantly but the economic significance is of this effect is limited. Otherwise, our previous results remain valid in this subsample analysis.

One issue with the significance of the investment income ratio in our regressions is that the positive correlation between an insurer's investment income and its MES could be spurious because both variables could be driven by a firm's affiliation to the life insurance business. On the one hand, engaging in the life insurance business naturally influences an insurer's investment income ratio 
because it shifts the insurer's primary source of profits from underwriting to asset management. On the other hand, however, systemic risk exposure could also be higher for life insurers because of generally higher leverage, a higher potential of policyholder withdrawals during a financial crisis and the increasing popularity of policies that include variable annuities (Harrington, 2009; Cummins and Weiss, 2010; IAIS, 2012). To control for this possibility, we estimate an unreported regression in which we include a dummy variable that takes on the value one if an insurer is active in the life insurance business and zero otherwise. As expected, our life insurer dummy is strongly correlated with our Investment activity variable and moderately correlated with the investment income ratio. Using Investment success together with the life insurance dummy in our baseline setting, wee find that our main results remain unchanged. An insurer's investment income ratio remains a statistically and economically significant predictor of systemic risk exposure, whereas the life insurer dummy does not enter the regression with a significant coefficient.

We also estimate an unreported regression of MES in which we use all insurers in our full sample but only employ the three main variables from the IAIS methodology. The exclusion of the remaining hypothesized indicators of systemic relevance increases the adjusted $R^{2}$ compared to regression (1) from 0.455 to 0.496 . None of the additional insurer characteristics for which we control enter this regression with a significant coefficient. Thus, the main result from this analysis is that again we find an insurer's exposure to turmoil in the financial sector to be increasing in firm size, stronger activity and success in asset management and higher non-policyholder liabilities.

We also examine whether the effects that we find between an insurer's MES and several of our firm characteristics are driven by the inclusion of reinsurers in our sample. The findings in the previous literature on the question of whether reinsurers increase or mitigate the danger of a systemic crisis are inconclusive. For example, a study by Swiss Re (2003) concludes that reinsurance insolvencies do not pose a systemic risk because primary insurers usually spread their reinsurance cessions across several reinsurers and across countries. A similar stance is taken by the Group of Thirty (2006), which argues that even the defaults of large portions of 
the reinsurance business would not lead to contagion in the global financial sector. ${ }^{26}$ However, Cummins and Weiss (2010) argue that reinsurers could be vulnerable to a retrocession spiral whereby the failure of major reinsurers triggers the failure of their reinsurance counterparties. As a result, the defaults of several reinsurers could then spill over to primary insurers and possibly to other financial intermediaries. To control for a bias in our results caused by the inclusion of reinsurers, we estimate an unreported regression in which we only use the primary insurers in our sample (and excluding 16 reinsurers). Firms are classified as reinsurers if they assume more than $50 \%$ of their total written premiums from reinsurance or if the firm name suggests that reinsurance is the firm's major line of business. Untabulated results on the average MES show that reinsurers are less exposed to systemic risk $(\mathrm{MES}=5.07 \%)$ than primary insurers (MES=6.88\%). Reinsurers, however, are still considerably vulnerable to financial instability. Furthermore, the results on the hypothesized drivers of an insurer's systemic relevance also hold when excluding reinsurers. Insurer size, investment success and non-policyholder liabilities remain both statistically and economically significant predictors of MES in our regression.

In regressions (6) to (10), we address the related question which factors drive an insurer's contribution to systemic risk. We use the same sets of explanatory variables as before but use the $\Delta \mathrm{CoVaR}$ of U.S. insurers as our dependent variable in these regressions. In our regression baseline regression (6), Total assets is identified as a significant determinant of an insurer's contribution to systemic risk with a one-standard-deviation increase in insurer size decreasing the insurer's $\Delta$ CoVaR by 0.40 percentage points $(-0.002 \times 1.993)$. The only other significant variable in this setting is Other income, which enters regression (6) with a weakly significant positive sign. It is important to note that the adjusted $R^{2}(8.6 \%)$ is considerably lower in the regression of $\Delta \mathrm{CoVaR}$ than in the regression of MES. Regression (7) adds leverage to our baseline regression. This analysis is not successful as leverage does not enter this regression with a significant coefficient and the adj. $R^{2}$ is negligible $(0.6 \%)$. Including the loss ratio of insurers in regression (8) does not

26 The few related studies in this field arrive at similar conclusions. For example, the hypothesis that reinsurers are not a source of contagion is empirically confirmed for the Dutch insurance sector by the study of van Lelyveld et al. (2011). 
change our conclusions. Insurer size and Other income remain the only significant determinants of an insurer's systemic risk contribution. In regression (9), we further include Liquidity betas and LTCM returns and find the former to be significantly positively correlated with $\Delta$ CoVaR. In line with our expectation, insurers that had invested in more illiquid assets before the crisis (and were not able to easily sell of assets at fair value during the crisis) contributed less to systemic risk. Otherwise, our results remain unchanged. Finally, regression (10) uses only the sub-sample nonlife insurers. In this regression, Total assets and Other income loses all their statistical significance. Conversely, assuming more premiums from reinsurance has a stabilizing effect on systemic risk for non-life insurers. At the same time, engaging in too many specialty lines of insurance and a larger board size both increase a non-life insurer's contribution to systemic risk.

Next, we turn to a sensitivity analysis of the level of explanatory power that our independent variables possess. The results of this analysis are presented in Table $\nabla$.

- insert Table $\mathrm{V}$ here -

Again, we repeat our regressions using both the insurers' MES (Panel A) and $\triangle \mathrm{CoVaR}$ (Panel B) as our dependent variables. Regressions (1) through (10) each use the IAIS indicators of systemic relevance one at a time. The results in Panel A from the regressions of MES show that an insurer's size, investment income ratio, investment activity and reliance on non-policyholder liabilities are all highly significantly positively related to the insurer's MES. The adjusted $R^{2}$ is highest (41.8\%) for regression (1) in which we employ Total assets as the only independent variable. Regressions (2) through (4) also exhibit significant levels of explanatory power with an adjusted $R^{2}$ of $19.8 \%, 20.6 \%$ and $7.7 \%$, respectively. Regression (11) uses all indicators proposed by the IAIS. Using the full set of indicators, however, does not significantly improve the model's explanatory power because the adjusted $R^{2}$ only increases by 4.2 percentage points compared to model (1). We thus find further evidence that insurer size, higher investment activity and non-policyholder liabilities are the key drivers of systemic risk exposure in the insurance industry. In Panel B of Table $\mathrm{V}$, we repeat our sensitivity analysis for by regressing $\triangle \mathrm{CoVaR}$ on the IAIS variables one at a time. The results from this analysis clearly show that insurer size is the only relevant determinant of an 
insurer's contribution to the systemic risk of the U.S. financial system with all other IAIS factors being statistically insignificant.

Our results thus far stress the findings that large U.S. insurers both contributed and were exposed to considerable systemic risk during the financial crisis and that the systemic risk exposure of insurers as measured by an insurer's MES was predominantly driven by size, non-traditional financing and the reliance on investment income. At the same time, an insurer's contribution to systemic risk seems to be driven only by insurer size. An important question to address in this context is whether MES and $\triangle \mathrm{CoVaR}$ themselves are suitable measure of systemic risk. Moreover, a regulator's decision on the question of whether an insurer is systemically important is a dichotomous one. To this end, we first define the systemically most exposed financial institutions as those firms that were in the top MES quartile during the crisis. Admittedly, this definition of systemically relevant insurers is somewhat arbitrary. Nevertheless, we believe this criterion to be sufficiently selective because the sub-sample of insurers in the top MES quartile includes all six U.S. insurers that received bailouts under the U.S. government's Troubled Asset Relief Program. Second, we define the most systemically important insurers as those companies that required aid under TARP. Table VI shows the results of probit regressions of the membership in the top MES quartile on the same set of explanatory variables used in our linear regressions. All specifications report marginal effects. Additionally, we estimate probit regressions of a dummy variable that takes on the value one if an insurer received a bailout under TARP.

$$
\text { - insert Table VI here - }
$$

Insurer size, investment income and non-policyholder liabilities before the crisis are all associated with a higher probability of becoming severely exposed to systemic risk during the subprime crisis. The effects that we find for these three factors are both statistically and economically significant. In our most comprehensive model specification (4), a one-standard-deviation increase in insurer size increases the probability of an insurer belonging to the top MES quartile by 13.95 $(0.070 \times 1.993)$ percentage points. Correspondingly, a one-standard-deviation increase in an insurer's investment income ratio and non-policyholder liabilities are associated with increases of 
$5.86 \%(0.434 \times 0.135)$ and $7.33 \%(0.320 \times 0.229)$, respectively, in the probability of suffering the most externalities due to the crisis. The remaining variables have no power for predicting an insurer's membership in the top MES quartile. Overall, the results of the probit regressions are consistent with our previous results. While our linear regressions emphasize that size, non-traditional funding and reliance on investment income increase an insurer's systemic risk exposure, the probit regressions corroborate the finding that these three indicators can indeed be used to identify insurers that suffered the most during the financial crisis. In addition, we also estimate probit regressions of the probability to receive a bailout under TARP. In line with our findings from the analysis of the insurers' $\Delta \mathrm{CoVaR}$ estimates, the contribution of an insurer to systemic seems to be only driven by insurer size. We find in regression (9) that a one-standard-deviation increase in firm size is associated with a $11.56 \%(0.058 \times 1.993)$ increase in the likelihood of requiring a bailout under TARP. The remaining factors proposed by the IAIS do not have significant predictive power for an insurer's systemic importance.

\subsection{Robustness checks}

In addition to the regressions discussed earlier in Section 3.2, we investigate the robustness of our results using several other specifications and other data. To save space, the results of these robustness checks are not tabulated but are available from the authors upon request. Our main regression is based on a relatively small data sample of 89 observations. Consequently, the results that we find could be driven by a few outliers, such as AIG. To tackle this possible problem and to minimize the confounding effect of outliers, we estimate median regressions that aim at approximating the conditional median of our response variable. Our main conclusions on the determinants of an insurer's MES are robust to this additional specification. The coefficients on total assets, investment success and non-policyholder liabilities remain strongly economically and statistically significant in these regressions.

Some of our explanatory variables, such as Loss ratio, exhibit extreme outliers for some insurers. To control for the possibly biasing influence of these outliers on our results, we estimate 
regressions in which we winsorize our explanatory variables at the $1 \%$ and $99 \%$ quantiles (see Fahlenbrach et al., 2012, for a similar approach). We find that our findings are qualitatively and quantitatively robust to this alternative specification. We also employ the variable Net revenues as an alternative to Total assets in our regressions. The correlation between both variables is 0.94 , and not surprisingly, our cross-sectional results remain unchanged when using Net revenues to proxy for insurer size.

We also estimate several other regressions similar to those in Table IV] using the liquidity betas and LTCM returns in different regression specifications. In addition, we estimate regressions in which we use an insurer's return on assets as a further explanatory variable. Using this approach does not change our conclusions. Whereas both Liquidity beta and Return on assets enter none of our regressions with significant coefficients, the insurers' buy-and-hold returns during the LTCM crisis are strongly negatively correlated with the insurers' exposure to systemic risk during the financial crisis in these alternative models.

Next, one might be concerned that our results are mostly driven by our choice of a financial sector index in the computation of the insurers' Marginal Expected Shortfalls. As a robustness check, we re-estimated an insurer's MES using the Datastream US Full Line Insurance Index to proxy for the insurance market's return. The differences between the two approaches are indistinguishable from zero because the MES estimates for the two indexes show a positive correlation of $99.86 \%$. It could also be criticized that the use of a narrow sector index could bias the MES estimates upwards as within-industry correlations are generally higher than across-industry correlations. Consequently, we also re-estimate our measures of systemic risk using the broader S\&P 500 index instead of a sector index. Doing so does not change our findings reported in the previous sections. Moreover, it could be argued that our static estimation of the MES does not appropriately account for possible time variation in an insurer's contribution to systemic risk. In particular, our results may be primarily driven by just a few days around the collapse of Lehman Bros. on which all markets around the world plummeted. To address this concern, we estimate regressions in which we use the average MES estimated dynamically from the model of Brownlees and Engle (2012) as 
our dependent variable. Furthermore, we split our sample period in half and re-estimate the MES for both sub-samples before and around the collapse of Lehman and AIG. We then estimate regressions based on both sub-samples as well as using the $\Delta$ CoVaR estimates as dependent variables. Again, we find that our main conclusions are unaltered by these alternative specifications.

In addition to MES and $\triangle \mathrm{CoVaR}$, we also estimate the SRISK measure of Brownlees and Engle (2012) and Acharya et al. (2012). Descriptive statistics on SRISK and Total SRISK are given in Table I. Furthermore, we estimate unreported regressions of Total SRISK on the IAIS and control variables. The estimates on Total SRISK underline the notion that most smaller insurers did not contribute significantly to systemic risk. However, several large insurers including, e.g., AIG, Prudential, Metlife and Genworth have Total SRISK estimates that imply a considerable contribution to overall systemic risk. Most importantly, our regressions of Total SRISK confirm the robustness of our findings from the previous analysis of $\Delta \mathrm{CoVaR}$. The contribution of an insurer to systemic risk as measured by its Total SRISK is driven predominantly by insurer size and, to a lesser extent, by the insurer's global activity and the number of business line the insurer is active in.

A further potential problem with our regressions is that our results could be driven by unobserved differences in state regulation of insurers in the U.S. For example, both the exposure and contribution of insurers to systemic risk could be influenced by different statutory reserve regulation or differences in state guarantee funds across U.S. federal states (see also Koijen and Yogo, 2013). To control for this possible obmitted variable bias, we estimate additional regressions where we control for state fixed effects. The unreported results show that our findings from Section 3.2 remain quantitatively and qualitatively the same.

Finally, we estimate an insurer's MES and $\triangle \mathrm{CoVaR}$ based on alternative definitions of the crisis period. To be precise, we estimate MES and $\triangle \mathrm{CoVaR}$ using the periods of December 2007 to June 2009 and July 2007 to December 2009. Using these periods does not change our findings. 


\section{Conclusions}

In this paper, we find that several insurers contributed significantly to the instability of the U.S. financial sector during the recent financial crisis. We find that an insurer's size, its reliance on investment income and non-policyholder liabilities before the crisis predict its exposure to systemic risk during the recent financial crisis. At the same time, the contribution of an insurer to systemic risk is predominantly driven by its firm size. The economic magnitudes of these effects are highly significant and our results hold regardless of whether we include reinsurers in our sample. Furthermore, our key result on the positive correlation between an insurer's investment income ratio and its systemic risk contribution cannot be explained by differences in the income sources of life and non-life insurers because we find similar results for both business lines.

Given our main results on the key determinants of an insurer's systemic risk contribution, the current initiative of the IAIS for identifying globally systemically important insurers must be re-evaluated. Our findings are only partially consistent with the current hypotheses of insurance regulators on the origins of systemic risk in the insurance industry. Hypotheses regarding the destabilizing side effects of non-traditional financing and investment income, as well as the toobig-to-fail hypothesis, are all strongly supported by our analyses. In contrast, we find no evidence that supports the view of regulators that leverage, global diversification, short-term funding or substitutability significantly increase an insurer's contribution to systemic risk. Our results emphasize that the current plans of the IAIS require considerable improvement. Global activity and the offer of specialty insurance should not be penalized by regulators because these factors do not cause an insurer to become systemically relevant. Our evidence shows, however, that insurers can pose a threat to financial stability simply by becoming too-big-to-fail.

The practical importance of our analysis to regulators and supervisors is significant. Insurers that had the highest systemic risk contribution in our estimations included all U.S. insurers that required assistance from the U.S. government under TARP during the crisis. The proxies that we use for an insurer's systemic risk contribution are thus excellently suited for identifying institutions that became systemically relevant during the crisis. Again, we find that size, non-policyholder 
liabilities and investment income are significant predictors of an insurer's probability of becoming significantly exposed to adverse effects in a crisis. At the same time, the probability of requiring a TARP bailout can only be explained by an insurer's firm size.

Although we demonstrate that insurers did contribute to systemic risk during the crisis, our analysis should not be misinterpreted as an investigation into the origins of the crisis. While our empirical evidence supports the notion that insurers (such as AIG) contributed to systemic risk, we do not analyze the question of whether insurers also triggered (at least in part) the events leading to the crash in 2008. In addition, our study is concerned with the systemic risk contribution of the U.S. insurance industry only. Further research should attempt to analyze global insurers' contribution to systemic risk and to determine whether differences in global insurance regulation can affect an insurer's systemic relevance. 


\section{Appendix I: Sample Insurance Companies.}

The appendix lists all insurance companies that are used in the empirical study. The sample is constructed by first selecting all insurers from the country and dead-firm lists of Thomson Reuters Worldscope. The list is then corrected for all companies for which no 10-K filings could be found in the Morningstar Document Research database for the year 2006. Companies in the Worldscope and Morningstar databases are matched according to their ticker symbol. The names of the companies are then retrieved from the Worldscope database (item WC06001) and sorted according to their ticker symbol.

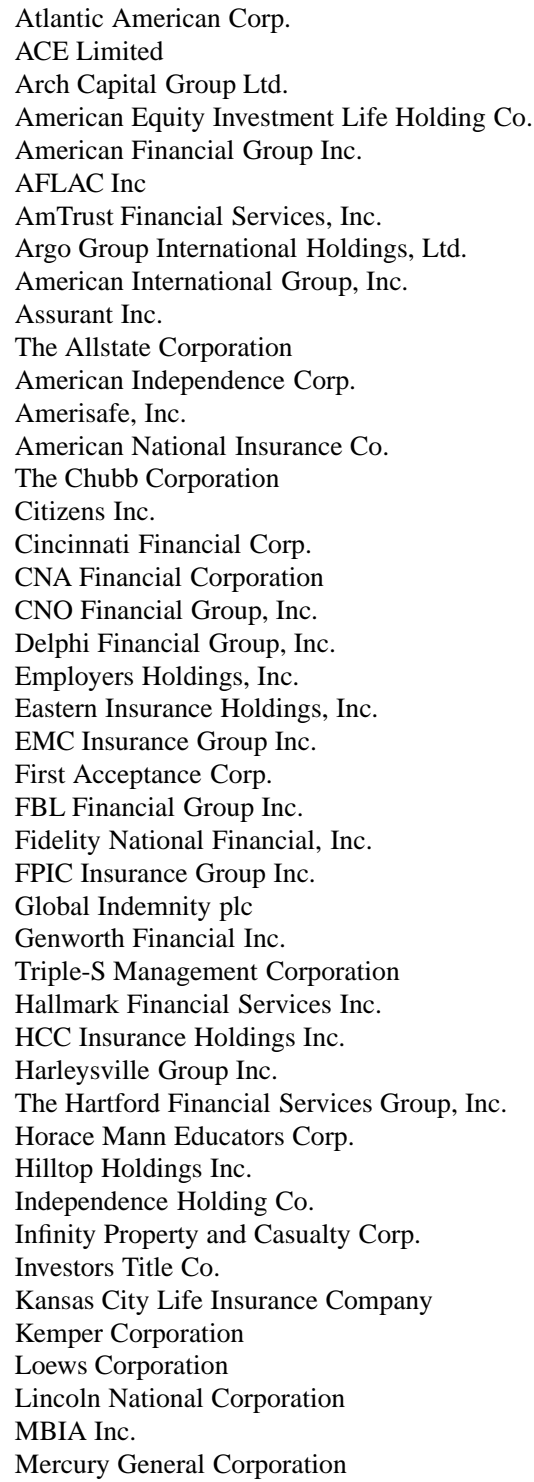

MetLife, Inc.

Meadowbrook Insurance Group Inc.

Markel Corp.

MGIC Investment Corp.

National Interstate Corporation

Navigators Group Inc.

National Security Group Inc.

National Western Life Insurance Company

OneBeacon Insurance Group, Ltd.

Old Republic International Corp.

Principal Financial Group Inc.

Progressive Corp.

Presidential Life Corp.

Phoenix Companies Inc.

Protective Life Corporation

ProAssurance Corporation

PartnerRe Ltd.

Prudential Financial, Inc.

Radian Group Inc.

Everest Re Group Ltd.

Reinsurance Group of America Inc.

RLI Corp.

RenaissanceRe Holdings Ltd.

Safety Insurance Group Inc.

SeaBright Holdings, Inc.

StanCorp Financial Group Inc.

Selective Insurance Group Inc.

Stewart Information Services Corporation

State Auto Financial Corp.

Federated National Holding Company

The Hanover Insurance Group Inc.

Torchmark Corp.

Transatlantic Holdings Inc.

The Travelers Companies, Inc.

Tower Group Inc.

United Fire Group, Inc.

Unico American Corp.

Unum Group

Universal Insurance Holdings Inc.

Validus Holdings, Ltd.

W.R. Berkley Corporation

White Mountains Insurance Group, Ltd.

XL Group plc

Alleghany Corp. 


\section{Appendix II: Variable definitions and data sources.}

The appendix presents definitions as well as data sources for all dependent and independent variables that are used in the empirical study.

\begin{tabular}{|c|c|}
\hline Variable name & Definition \\
\hline Systemic risk measures & \\
\hline MES & $\begin{array}{l}\text { Marginal Expected Shortfall as defined in Acharya et al }(2010) \text { as the average return on } \\
\text { an individual insurer's stock on the days the S\&P } 500 \text { Financials Sector Index experienced } \\
\text { its 5\% worst outcomes during the time period of July } 2007 \text { to December } 2008 \text {. }\end{array}$ \\
\hline Dynamic MES & $\begin{array}{l}\text { Dynamic Marginal Expected Shortfall as defined in Acharya et al, (2010) and calculated } \\
\text { following the procedure laid out by Brownlees and Engle (2012). }\end{array}$ \\
\hline$\Delta \mathrm{CoVaR}$ & $\begin{array}{l}\text { Unconditional } \triangle \mathrm{CoVaR} \text { as defined in Adrian and Brunnermeiet } 2010) \text {, measured as the } \\
\text { difference between the Value-at-Risk (VaR) of the S\&P 500 Financials Sector Index con- } \\
\text { ditional on the distress of a particular insurer and the VaR of the S\&P } 500 \text { Financials } \\
\text { Sector Index conditional on the median state of the insurer. }\end{array}$ \\
\hline Total SRISK & $\begin{array}{l}\text { Average annual estimate of the Systemic Risk Index as proposed by Acharya et al, (2012) } \\
\text { and Brownlees and Engle }(2012) \text {. The SRISK estimate for bank } i \text { at time } t \text { is given by } \\
S R I S K_{i, t}=k\left(D^{2} b t_{i, t}\right)-(1-k)\left(1-L R M E S_{i, t}\right) E q u i t y_{i, t} \text { where } k \text { is a regulatory capi- } \\
\text { tal ratio (set to } 8 \%) \text { Debti,t is the bank's book value of debt, } L R M E S_{i, t} \text { is the long run } \\
\text { Marginal Expected Shortfall defined as } 1-\exp \left(-18 \cdot d_{y n} M E S\right), d y n M E S \text { is the dynam- } \\
\text { ically estimated Marginal Expected Shortfall and Equity,t is the bank's market value of } \\
\text { equity. }\end{array}$ \\
\hline SRISK & $\begin{array}{l}\text { The contribution of insurer } i \text { at time } t \text { to aggregate SRISK. It is defined as } S R I S K \% \\
i, t=\frac{S_{\text {SISK }}, t,}{\sum_{j \in J} S R I S K_{j, t}} \text { with } J \text { being the set of all insurers in the sample with positive values } \\
\text { for Total SRISK. The estimates are then averaged over the crisis period as defined in our } \\
\text { empirical study. }\end{array}$ \\
\hline
\end{tabular}

Insurer characteristics Asset quality

Board size

Board independence

Fixed income

Income variability

Leverage

Life insurer

Liquidity beta

Loss ratio

LTCM return
Ratio of the value of bonds below investment grade (investment rating of $\mathrm{Ba} 1 / \mathrm{BB}+$ and lower) held by the insurer and total investments.

Natural logarithm of the number of directors on an insurer's board.

Percentage of independent outside directors on the board of directors.

Ratio of fixed income securities investment to total investment.

Standard deviation of the insurer's return on assets during the years 2004 to 2006.

Book value of assets minus book value of equity plus market value of equity, divided by market value of equity.

Dummy variable that takes on the value one for life insurers (SIC codes 6311, 6321) and zero otherwise.

The beta factor of an insurer with respect to liquidity innovations as defined by Pástor and Stambaugh (2003) using a regression of monthly stock returns in excess of the three-month T-bill rate during the years 2004-2006 on the excess returns of the S\&P 500 index and liquidity innovations.

Claim and loss expense plus long term insurance reserves divided by premiums earned.

Buy-and-hold return on an insurer's stock between August 3, 1998 until the trading day in 1998 on which the insurer's stock attained its lowest price. If the lowest price occured more than once, the return is calculated using the first date on which it occured (see Fahlenbrach et al, 2012).
Data source

Datastream, own. calc.

Datastream, own. calc.

Datastream, own. calc.

Datastream, own. calc.

Own. calc.

Worldscope (WC18701, WC02255), own calc.

ESG ASSET 4 (CGBSDP060) and Morningstar (DEF 14A filings).

ESG ASSET 4 (CGBSO07S) and Morningstar (DEF 14A filings).

Worldscope (WC02215, WC02255), own calc.

Worldscope (WC08326), own calc.

Worldscope (WC02999, WC03501, WC08001), own calc.

Worldscope (WC07021).

Datastream, own calc.

Worldscope (WC15549).

Datastream, own calc. 


\section{Appendix II: Variable definitions and data sources. (continued)}

\begin{tabular}{|c|c|c|}
\hline Variable name & Definition & Data source \\
\hline Market-to-book ratio & Market value of common equity divided by book value of common equity. & $\begin{array}{l}\text { Worldscope (WC07210, } \\
\text { WC03501), own calc. }\end{array}$ \\
\hline Operating efficiency & Ratio of operating expenses to total assets. & $\begin{array}{l}\text { Worldscope (WC01249, } \\
\text { WC02999), own calc. }\end{array}$ \\
\hline Return on assets & Pre-tax return on assets. & Worldscope (WC08326). \\
\hline Short-term funding & One minus long-term total debt divided by total debt. & $\begin{array}{l}\text { Worldscope (WC03251, } \\
\text { WC03255), own calc. }\end{array}$ \\
\hline \multicolumn{3}{|c|}{ Key IAIS indicators of systemic relevance } \\
\hline Assumed reinsurance & Ratio of assumed reinsurance premiums to total premiums written. & $\begin{array}{l}\text { Worldscope (WC01004) } \\
\text { and Morningstar }(10-\mathrm{K} \\
\text { filings). }\end{array}$ \\
\hline Ceded reinsurance & Ratio of written premiums ceded to reinsurance to total premiums written. & $\begin{array}{l}\text { Worldscope (WC01004) } \\
\text { and Morningstar (10-K } \\
\text { filings). }\end{array}$ \\
\hline Global activity & $\begin{array}{l}\text { Number of countries in which an insurer operates a sales office and/or subsidiary including } \\
\text { the home country. }\end{array}$ & $\begin{array}{l}\text { Morningstar }(10-\mathrm{K} \text { fil- } \\
\text { ings }) \text {, corporate websites. }\end{array}$ \\
\hline Investment success & Ratio of the insurer's investment income to net revenues. & $\begin{array}{l}\text { Worldscope (WC01001, } \\
\text { WC01006), own calc. }\end{array}$ \\
\hline Investment activity & $\begin{array}{l}\text { Ratio of the insurer's absolute investment income to the sum of absolute investment in- } \\
\text { come and absolute earned premiums. }\end{array}$ & $\begin{array}{l}\text { Worldscope (WC01002, } \\
\text { WC01006), own calc. }\end{array}$ \\
\hline $\begin{array}{l}\text { Non-policyholder liabili- } \\
\text { ties }\end{array}$ & $\begin{array}{l}\text { Ratio of the total on balance sheet liabilities minus total insurance reserves (including ben- } \\
\text { efit and loss reserves, unearned premiums, policy and contract claims and other reserves) } \\
\text { to total liabilities. }\end{array}$ & $\begin{array}{l}\text { Worldscope (WC03351, } \\
\text { WC03030), own calc. }\end{array}$ \\
\hline Net revenues & Log value of total operating revenue of the insurer. & Worldscope (WC01001). \\
\hline Other income & $\begin{array}{l}\text { Other pre-tax income and expensesbesides operating income, non-operating interest in- } \\
\text { come, interest expense on debt, interest capitalized, pre-tax extraordinary charge, pre-tax } \\
\text { extraordinary credit and increase/decrease in reserves. }\end{array}$ & Worldscope (WC01262). \\
\hline Substitutability & $\begin{array}{l}\text { Number of lines of specialty insurance (financial guarantee, mortgage guarantee, export } \\
\text { credit, marine and/or aviation coverage) in which an insurer operates. }\end{array}$ & $\begin{array}{l}\text { Morningstar } \quad(10-\mathrm{K} \text { fil- } \\
\text { ings }) \text {. }\end{array}$ \\
\hline Total assets & Natural logarithm of an insurer's total assets at fiscal year end 2006. & Worldscope (WC02999). \\
\hline
\end{tabular}




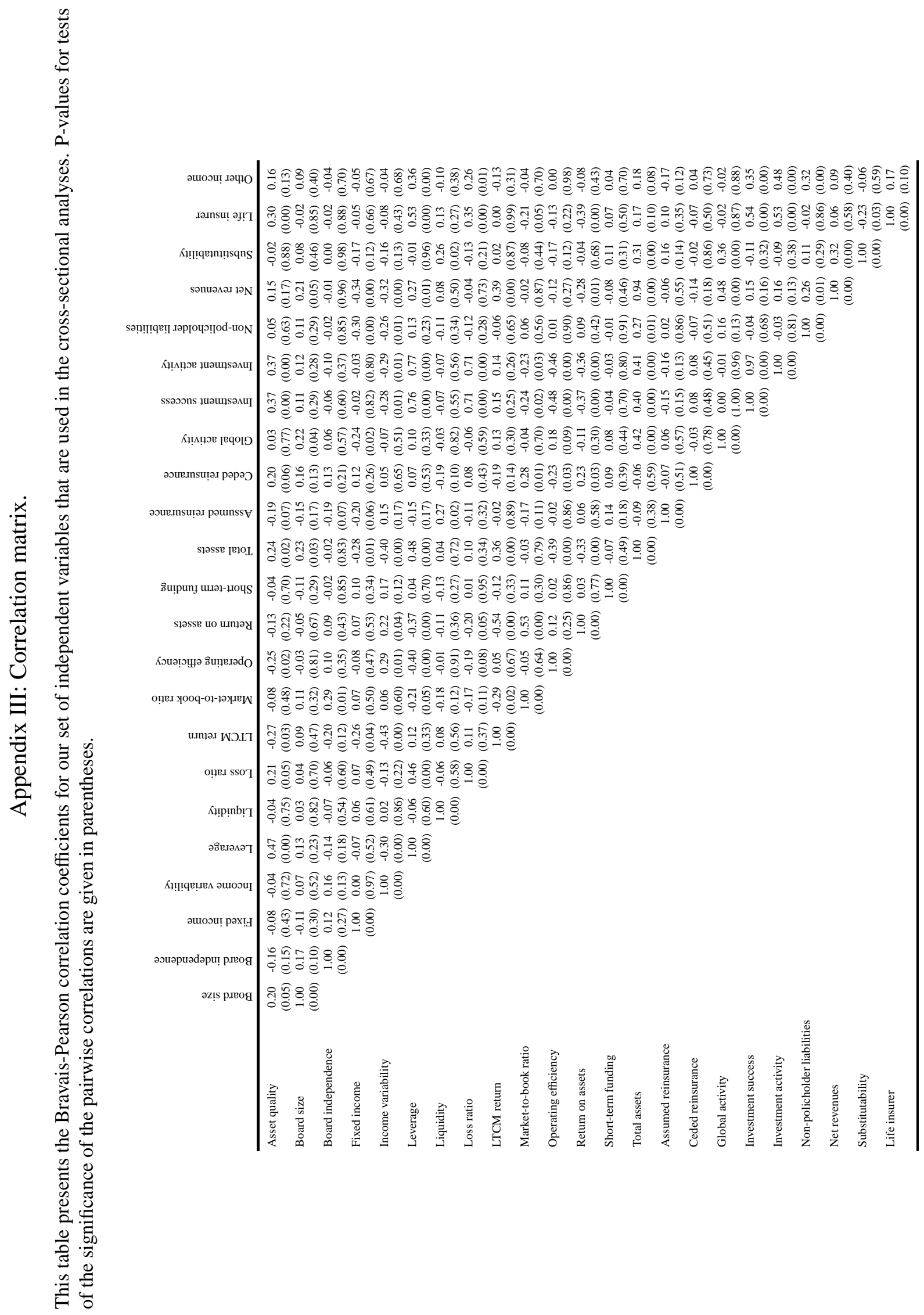




\section{References}

Acharya, V. V., J. Biggs, M. Richardson, and S. Ryan (2009): “On the Financial Regulation of Insurance Companies," Working paper, New York University.

Acharya, V. V., R. F. Engle, and M. Richardson (2012): “Capital Shortfall: A New Approach to Ranking and Regulating Systemic Risks," American Economic Review, 102(3), 59-64.

Acharya, V. V., L. H. Pedersen, T. Philippon, and M. Richardson (2010): “Measuring Systemic Risk," Working paper, New York University.

Adrian, T. and M. K. Brunnermeier (2010): “CoVaR,” Federal Reserve Bank of New York Staff Reports 348.

Adrian, T. AND H. S. SHIN (2010): “Market Liquidity and Funding Liquidity," Journal of Financial Intermediation, 19(3), 418-437.

Aebi, V., G. Sabato, and M. Schmid (2012): "Risk management, corporate governance, and bank performance in the financial crisis," Journal of Banking and Finance, 36, 3213-3226.

Bartram, S. M., G. W. Brown, And J. S. Conrad (2011): “The Effects of Derivatives on Firm Risk and Value," Journal of Financial and Quantitative Analysis, 46, 967-999.

Bartram, S. M., G. W. Brown, and R. M. Stulz (2012): “Why Are U.S. Stocks More Volatile?” Journal of Finance, 67(4), 1329-1370.

Beltratti, A. and R. M. Stulz (2012): "The Credit Crisis around the Globe: Why did some Banks perform better?" Journal of Financial Economics, 105, 1-17.

Benoit, S., G. Colletaz, C. Hurlin, and C. Pérignon (2013): “A Theoretical and Empirical Comparison of Systemic Risk Measures," Working Paper.

Billio, M., A. W. Lo, M. Getmansky, and L. Pelizzon (2012): "Econometric Measures of Connectedness and Systemic Risk in the Finance and Insurance Sectors," Journal of Financial Economics, 104, 535-559.

Brownlees, C. T. and R. Engle (2012): "Volatility, Correlation and Tails for Systemic Risk Measurement," Working Paper.

BrunNermeIER, M. K. (2009): “Deciphering the liquidity and credit crunch 2007-2008," Journal of Economic Perspectives, 23, 77-100.

Brunnermeier, M. K., G. Dong, and D. Palia (2012): “Banks’ Non-Interest Income and Systemic Risk," Working paper, Princeton University.

Brunnermeier, M. K. and L. H. Pedersen (2009): "Market Liquidity and Funding Liquidity," Review of Financial Studies, 22, 2201-2238. 
Chen, H., J. D. Cummins, K. S. Viswanathan, and M. A. Weiss (2012): "Systemic Risk and the Inter-Connectedness between Banks and Insurers: An Econometric Analysis," Journal of Risk and Insurance, forthcoming.

Cheng, I.-H., H. Hong, and J. A. Scheinkman (2010): "Yesterdays heroes: Compensation and creative risk-taking," NBER Working Paper No. 16176.

Cummins, J. D. And M. A. Weiss (2010): “Systemic Risk and the U.S. Insurance Sector,” Working paper, Temple University.

De HaAn, L. and J. Kakes (2007): “Are non-risk based Capital Requirements for Insurance Companies binding?" DNB Working paper No. 145/2007.

De Jonghe, O. (2010): "Back to the Basics in Banking? A Micro-Analysis of Banking System Stability," Journal of Financial Intermediation, 19, 387-417.

Diamond, D. W. AND R. G. Rajan (2009): “The credit crisis: Conjectures about causes and remedies," American Economic Review, 99, 606-610.

Engle, R. (2002): "Dynamic conditional correlation: A simple class of multivariate generalized autoregressive conditional heteroskedasticity models," Journal of Business and Economic Statistics, 20(3), 339-350.

Fahlenbrach, R., R. Prilmeier, and R. M. Stulz (2012): "This Time is the Same: Using Bank Performance in 1998 to Explain Bank Performance During the Recent Financial Crisis," Journal of Finance, 67, 2139-2185.

Fahlenbrach, R. and R. Stulz (2011): "Bank CEO incentives and the credit crisis," Journal of Financial Economics, 99, 11-26.

Geneva Association (2010): "Systemic Risk in Insurance - An Analysis of Insurance and Financial Stability,".

GrouP OF ThIRTY (2006): "Reinsurance and International Financial Markets,”.

Hagendorff, B., J. HagendorfF, and K. Keasey (2011): “The Risk Implications of Insurance Securization: Do Catastrophe Bonds lower the Default Risk of Issuers?" Working paper, University of Leeds.

Harrington, S. E. (2009): "The Financial Crisis, Systemic Risk, and the Future of Insurance Regulation," Journal of Risk and Insurance, 76, 785-819.

Hautsch, N., J. Schaumburg, and M. Schienle (2012): "Financial Network Systemic Risk Contributions," Discussion Paper 2012-053, CRC 649, Humboldt-Universität zu Berlin.

Hou, K., G. A. Karolyi, and B.-C. Kно (2011): "What Factors Drive Global Stock Returns?" Review of Financial Studies, 24(8), 2527-2574.

Hovakimian, A., E. Kane, and L. Laeven (2012): "Variation in Systemic Risk at US Banks During 1974-2010,” NBER Working Paper No. 18043. 
Huang, X., H. Zhou, and H. Zhu (2011): “Systemic Risk Contribution,” Board of Governors of the Federal Reserve System.

IAIS (2012): "Global Systemically Important Insurers: Proposed Assessment Methodology," Basel.

IMF (2010): “Global Financial Stability Report,” International Monetary Fund.

Ince, O. And R. Porter (2006): "Individual Equity Return Data From Thomson Datastream: Handle With Care!” Journal of Financial Research, 29, 463-479.

Karolyi, G. A., K.-H. Lee, and M. van DiJK (2012): "Understanding Commonality in Liquidity around the World," Journal of Financial Economics, 105(1), 82-112.

KoIJen, R. S. J. And M. Yogo (2013): “The Cost of Financial Frictions for Life Insurers," NBER Working Paper No. 18321.

Lewis, J. B. And D. A. Linzer (2005): "Estimating Regression Models in Which the Dependent Variable Is Based on Estimates," Political Analysis, 13, 345-364.

Longstaff, F. A. (2010): “The Subprime Credit Crisis and Contagion in Financial Markets," Journal of Financial Economics, 97, 436-450.

Milidonis, A. and Stathopoulos (2011): "Do U.S. Insurance Firms offer the "wrong” Incentives to their Executives?" Journal of Risk and Insurance, 78, 643-672.

Mishkin, F. S. (1999): "Financial consolidation: Dangers and opportunities," Journal of Banking and Finance, 23, 675-691.

Newey, W. and K. West (1987): "A simple, positive semi-definite, heteroskedasticity and autocorrelation consistent covariance matrix," Econometrica, 55, 703-708.

PÁstor, L. and R. F. Stambaugh (2003): “Liquidity risk and expected stock returns,” Journal of Political Economy, 111, 642-685.

Rabemananjara, R. And J.-M. ZakoÏAn (1993): “Threshold ARCH models and asymmetries in volatility," Journal of Applied Econometrics, 8, 31-49.

SchwaAb, B., S.-J. Koopman, and A. Lucas (2011): "Systemic risk diagnostics, coincident indicators and early warning signals," Technical report.

Swiss Re (2003): “Reinsurance - A Systemic Risk?” Sigma No. 5/2003.

Ulbricht, N. ANd C. Weiner (2005): "Worldscope meets Compustat: A Comparison of Financial Databases," Working paper, Humboldt University Berlin.

Vallascas, F. And J. Hagendorff (2011): “The Impact of European Bank Mergers on Bidder Default Risk," Journal of Banking and Finance, 35, 902-915.

Vallascas, F. and K. Keasey (2012): “Stability and Opacity in European Banks,” Working paper, Leeds University. 
van Lelyveld, I., F. Liedorp, and M. Kampman (2011): “An empirical assessment of reinsurance risk," Journal of Financial Stability, 7(4), 191-203.

Weiss, G. AND J. MüHLNICKel (2012): "Consolidation and Systemic Risk in the International Insurance Industry," Working Paper.

White, H., T.-H. Kim, and S. Manganelli (2012): "VAR for VaR: Measuring Tail Dependence Using Multivariate Regression Quantiles," European Central Bank Working Paper.

Yermack, D. (1996): "Higher market valuation of companies with a small board of directors," Journal of Financial Economics, 40, 185-211. 


\section{Tables and Figures}

Figure 1: U.S. bank and insurer returns during the financial crisis.

The figure shows the plots of the returns on the Datastream U.S. Life Insurance, U.S. Non-Life Insurance and U.S. Bank indexes as well as the Dow Jones Industrials Index. The data are taken from the Thomson Reuters Financial Datastream database and cover the period from 01/01/2007 to 12/31/2009. All data series of log returns are normalized to 100 at the start of 2007 .

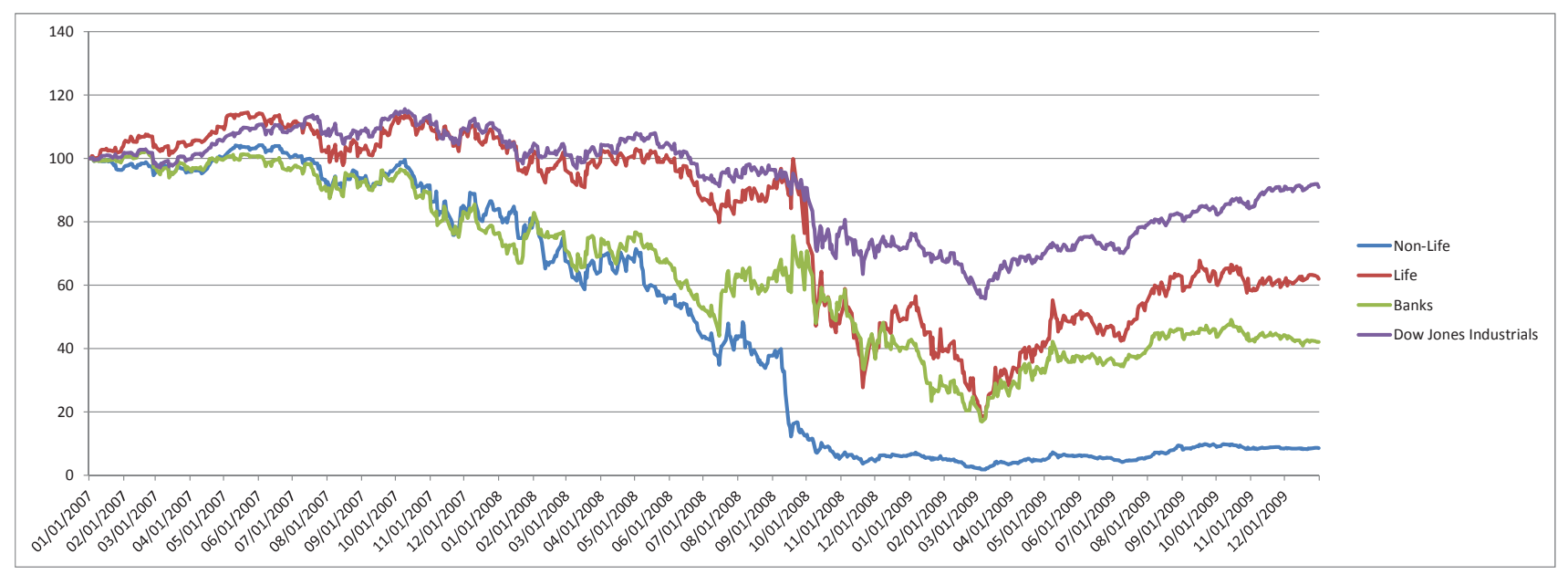


Figure 2: Daily Marginal Expected Shortfall of insurers during the financial crisis.

The figure shows daily estimates of the Marginal Expected Shortfall (MES) of U.S. insurers computed using the dynamic model specification of Brownlees and Engle (2012). For each day, estimates for all insurers between the 5\%and 95\%-quantiles (area shaded in grey) as well as the mean MES estimate (solid line) are shown. The sample consists of 89 U.S. insurers.

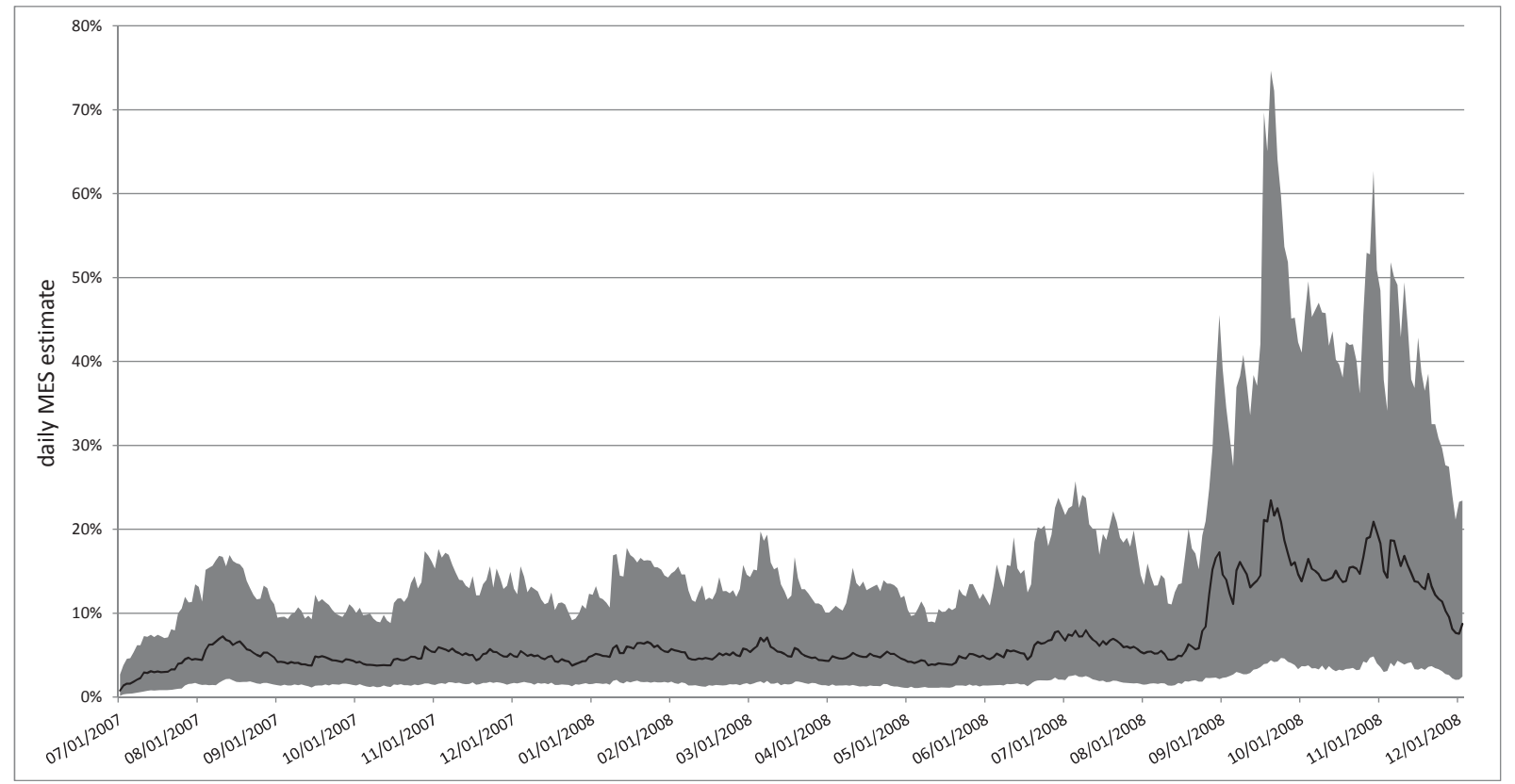

Figure 3: Systemic risk contribution versus systemic risk exposure.

The figure shows a scatter plot of the $\triangle \mathrm{CoVaR}$ estimates for U.S. insurers their respective Marginal Expected Shortfalls (MES). Variable definitions and data sources are provided in Appendix [II The sample consists of 89 U.S. insurers that are identified in the plot by their ticker symbols.

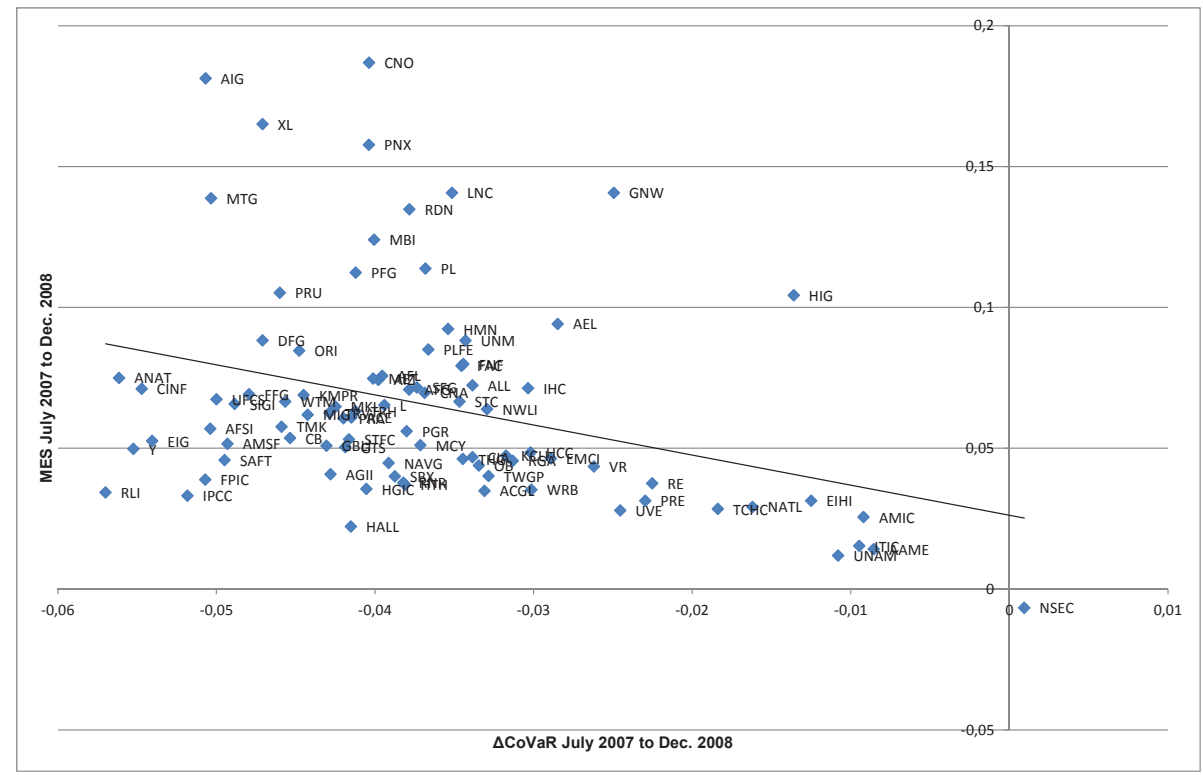


Figure 4: Insurer size predicts systemic relevance during the financial crisis.

The figure shows a scatter plot of the Marginal Expected Shortfall (MES) of U.S. insurers against the insurers' (log) total assets. Variable definitions and data sources are provided in Appendix II The sample consists of 89 U.S. insurers that are identified in the plot by their ticker symbols.

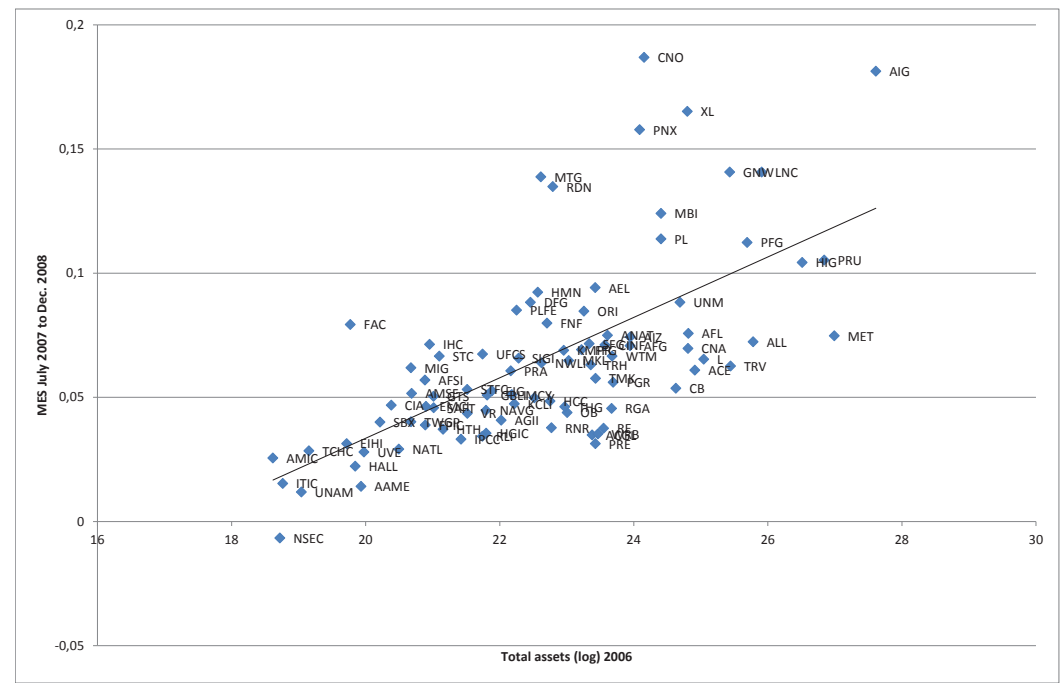

Figure 5: Investment success predicts systemic relevance during the financial crisis.

The figure shows a scatter plot of the Marginal Expected Shortfall (MES) of U.S. insurers against the insurers' ratio of investment income to net revenues. Variable definitions and data sources are provided in Appendix III] The sample consists of 89 U.S. insurers that are identified in the plot by their ticker symbols.

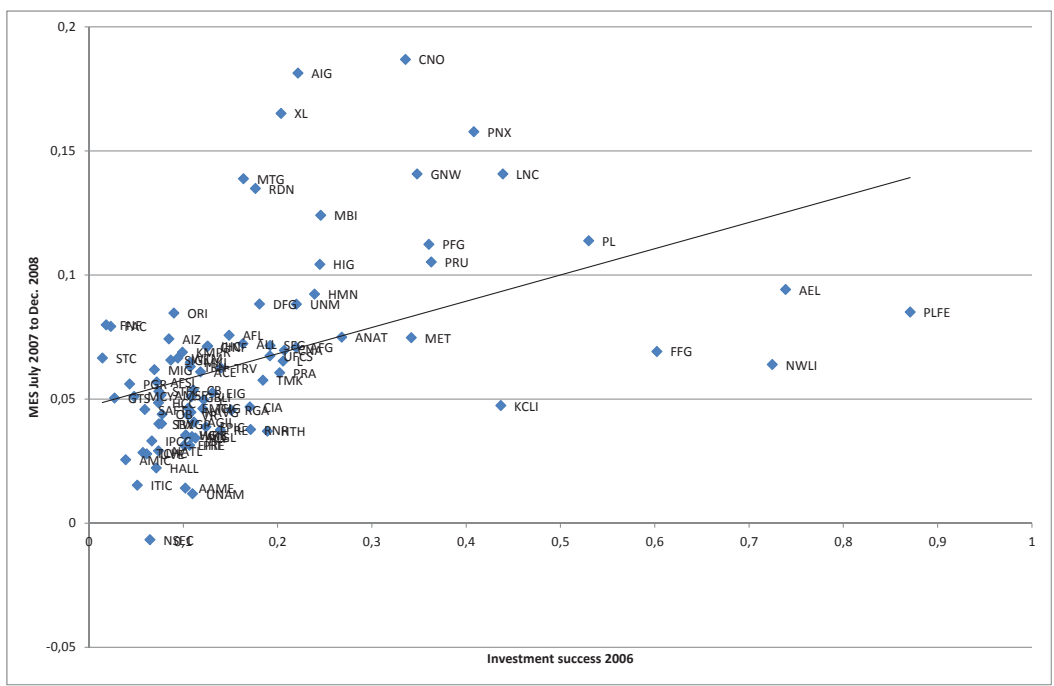


Table I: Descriptive statistics.

The table presents summary statistics for the sample of 89 U.S. insurers. All variables and data sources are defined in Appendix $\Pi$ Net revenues and Total assets are given in \$ billion. Total SRISK is given in \$ thousands. Accounting data are measured at the end of fiscal year 2006.

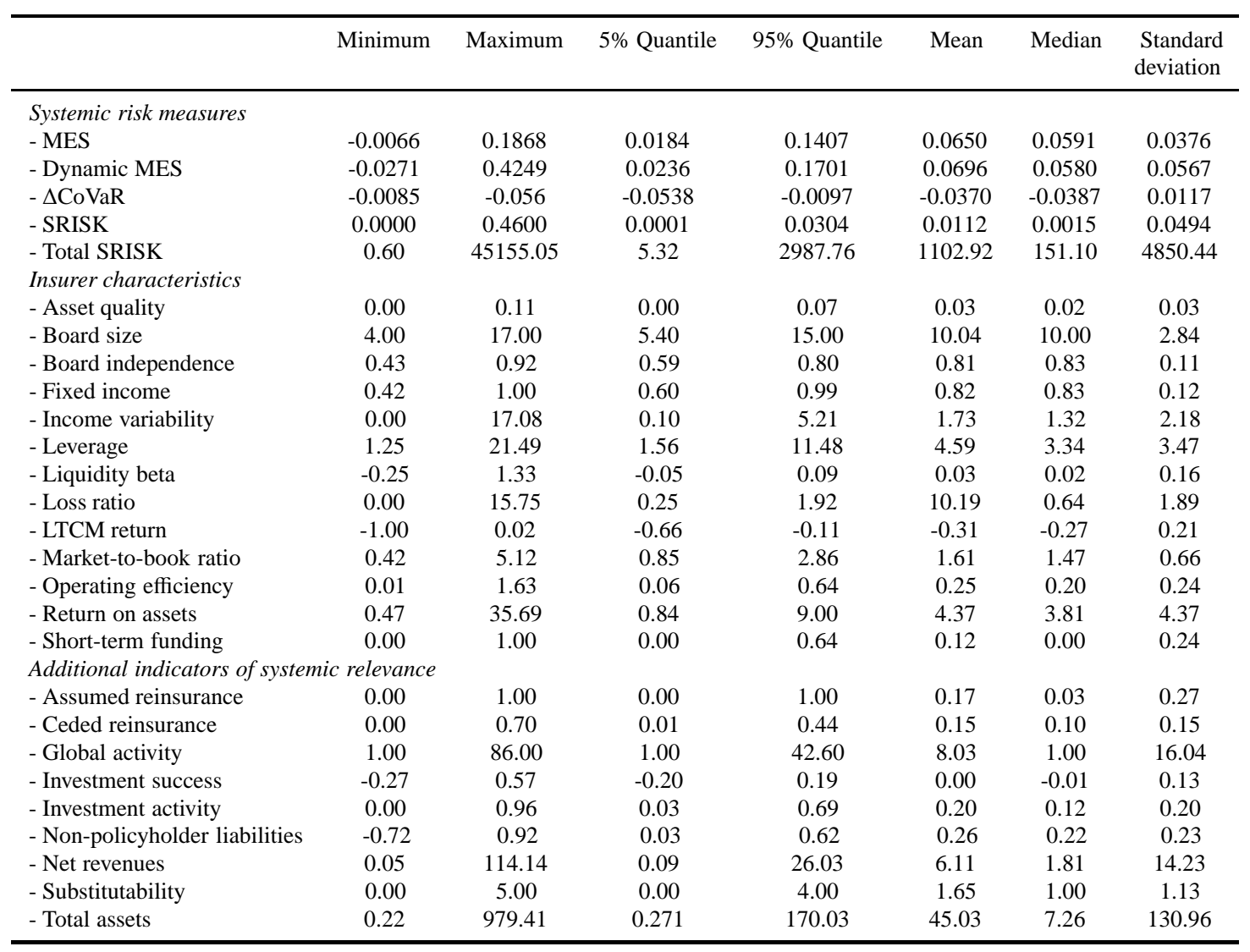




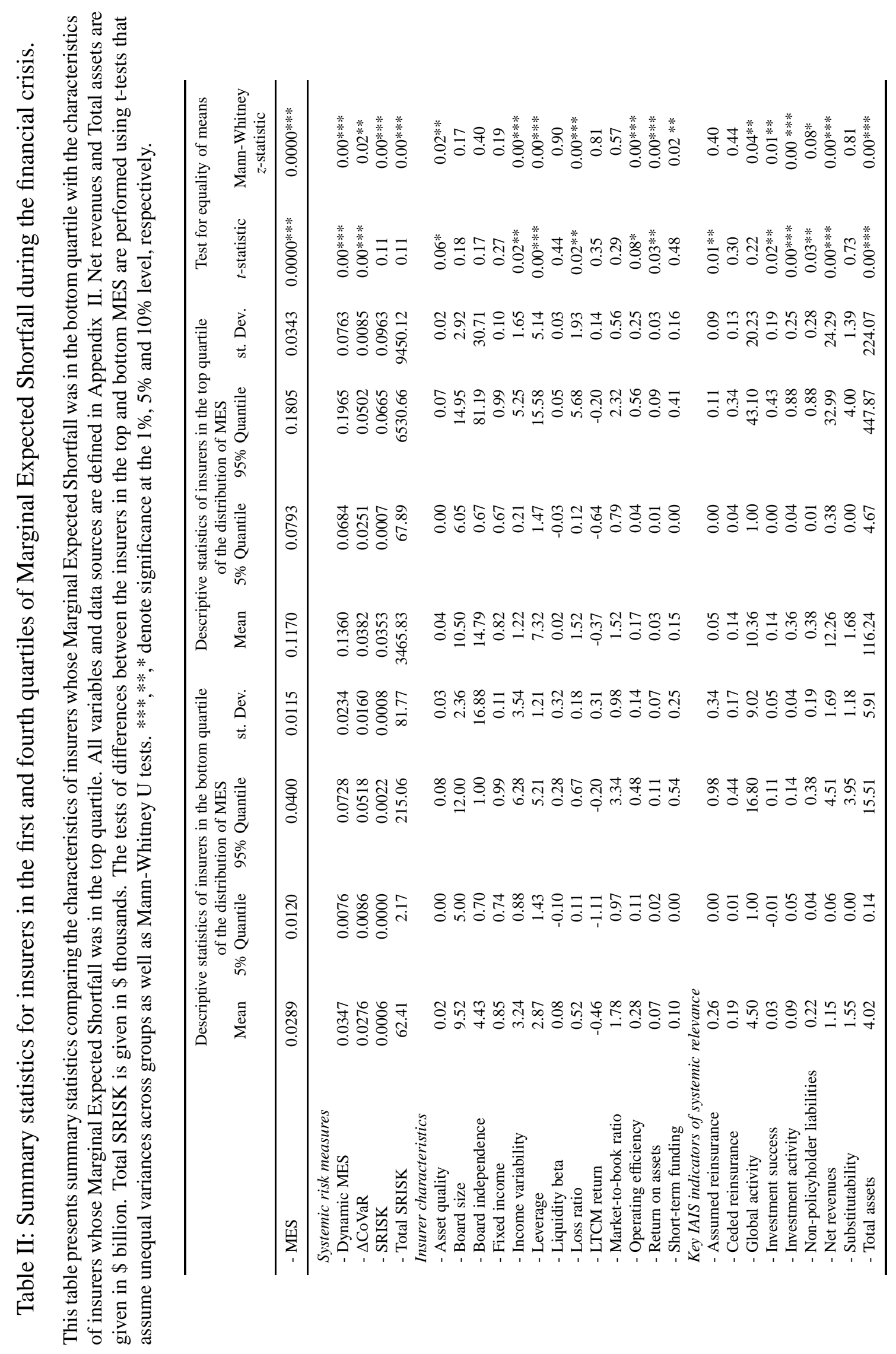




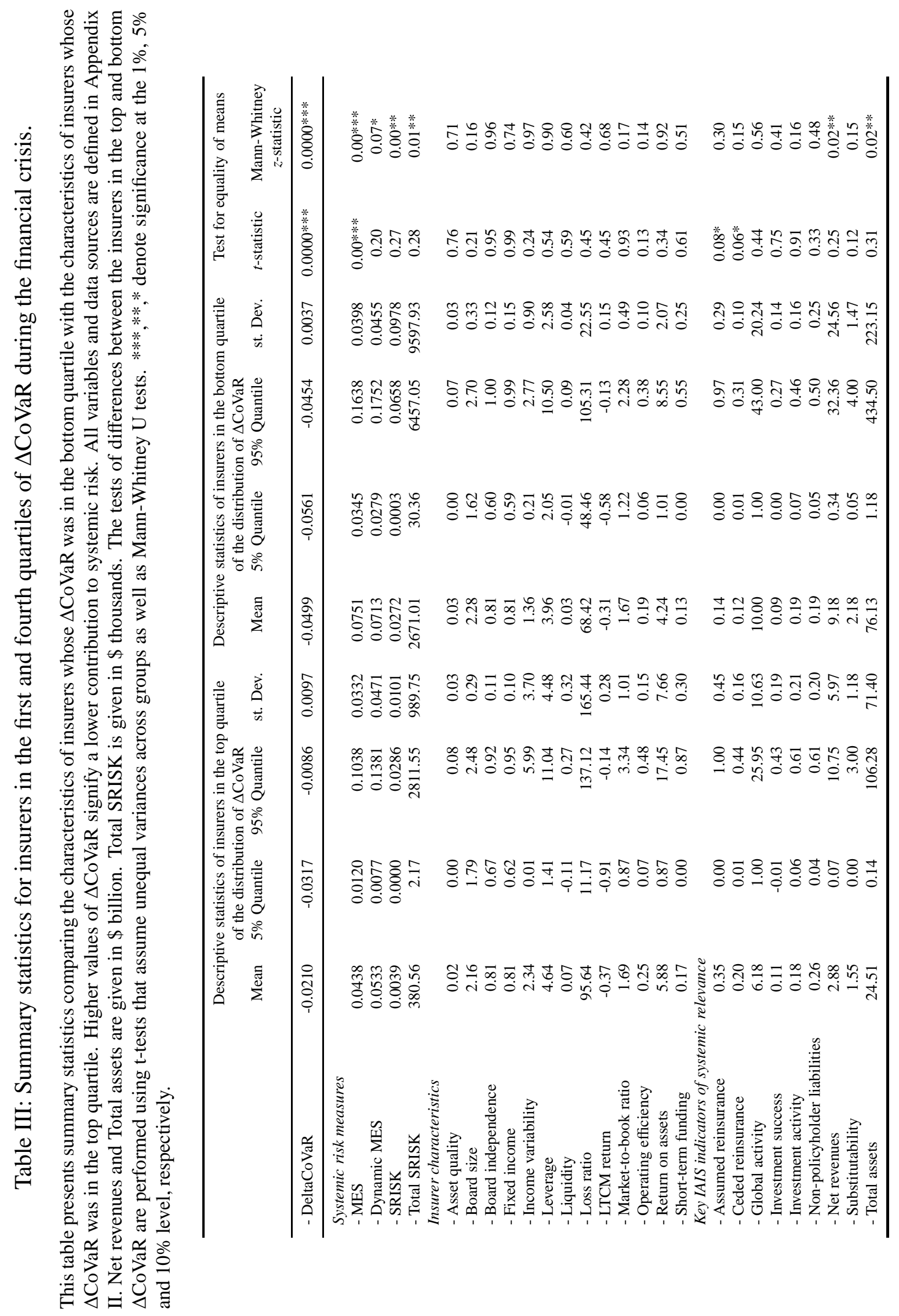


б 穴

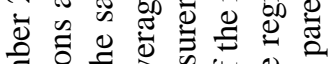
चี

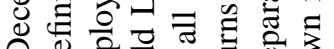

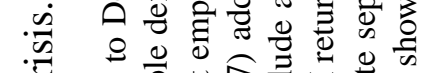
ड)

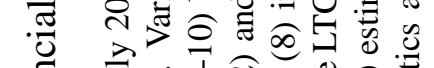

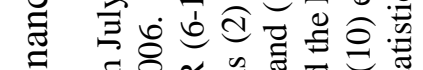
घ छ \& ఏ .

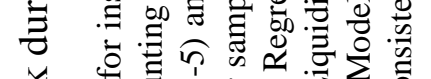
药 荡 ฮี 娄

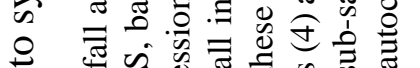

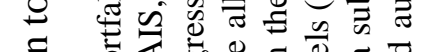

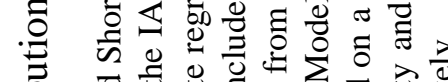

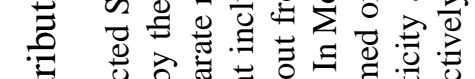

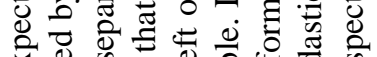

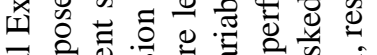
जٓ

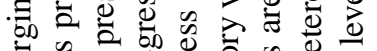

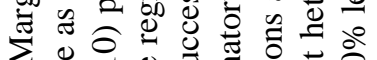

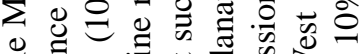

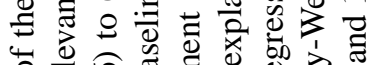
पे 0 。

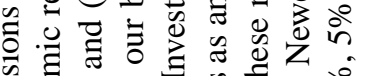

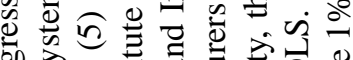

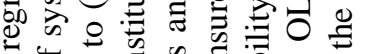
元 훙 0 \%

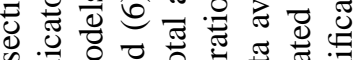

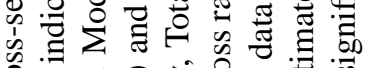

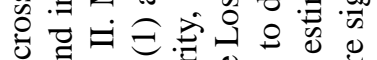
주 Е

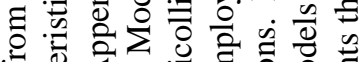
这的寻

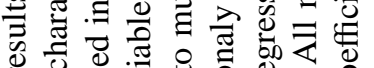
ग ป

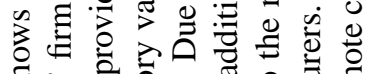

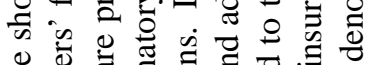

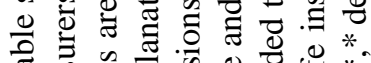

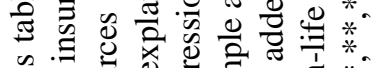

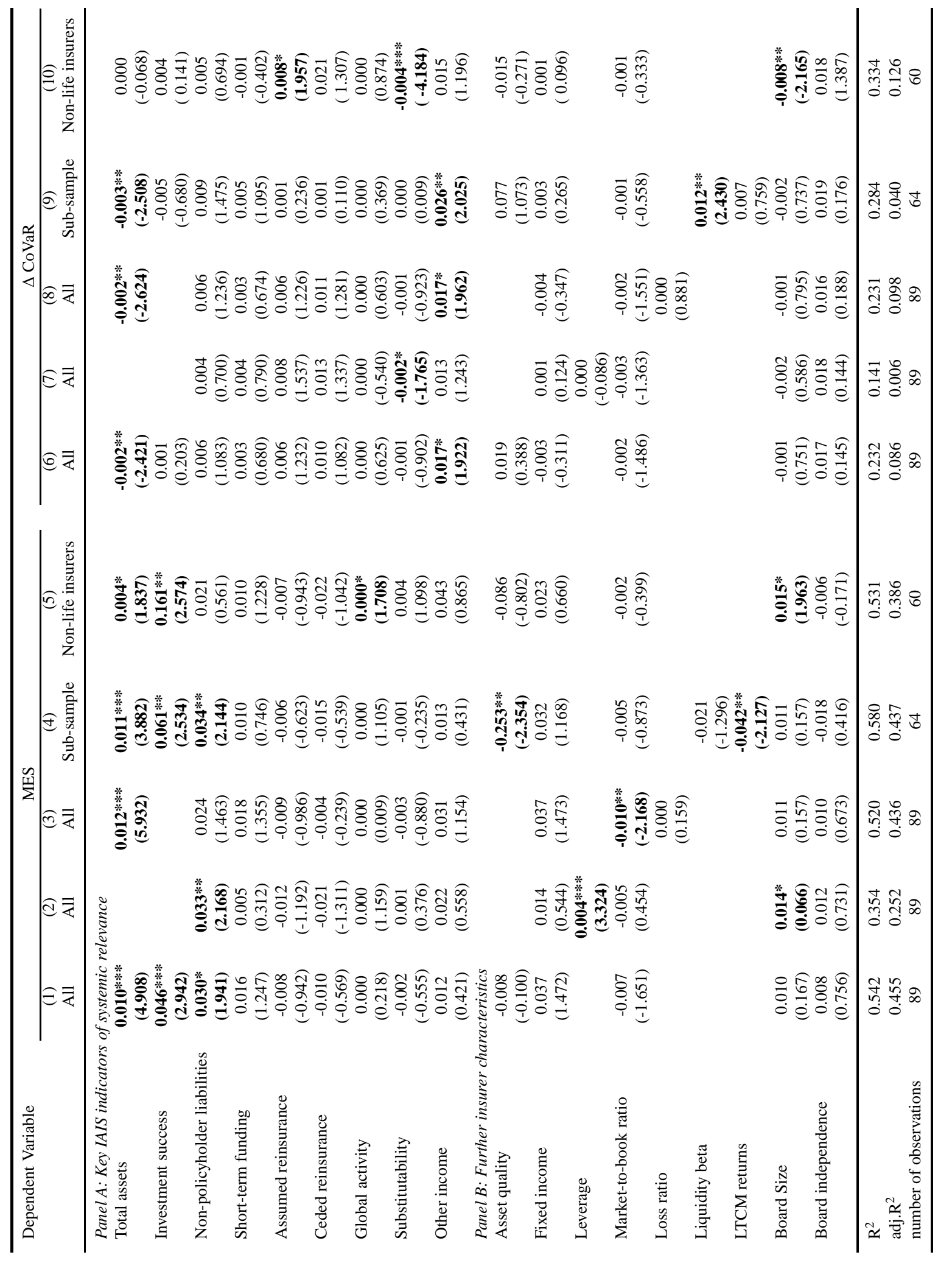

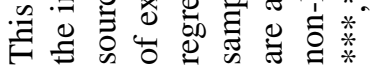




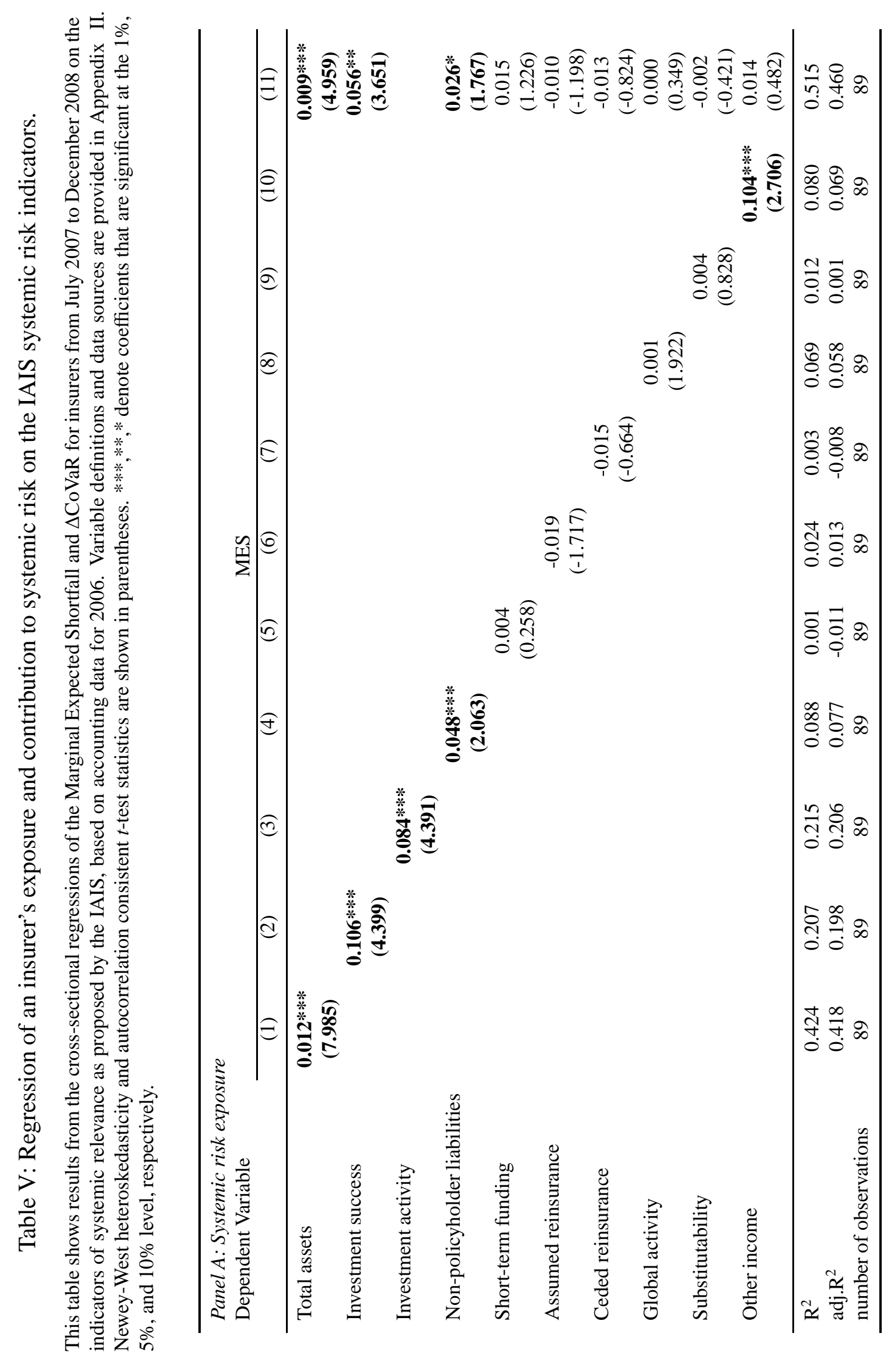




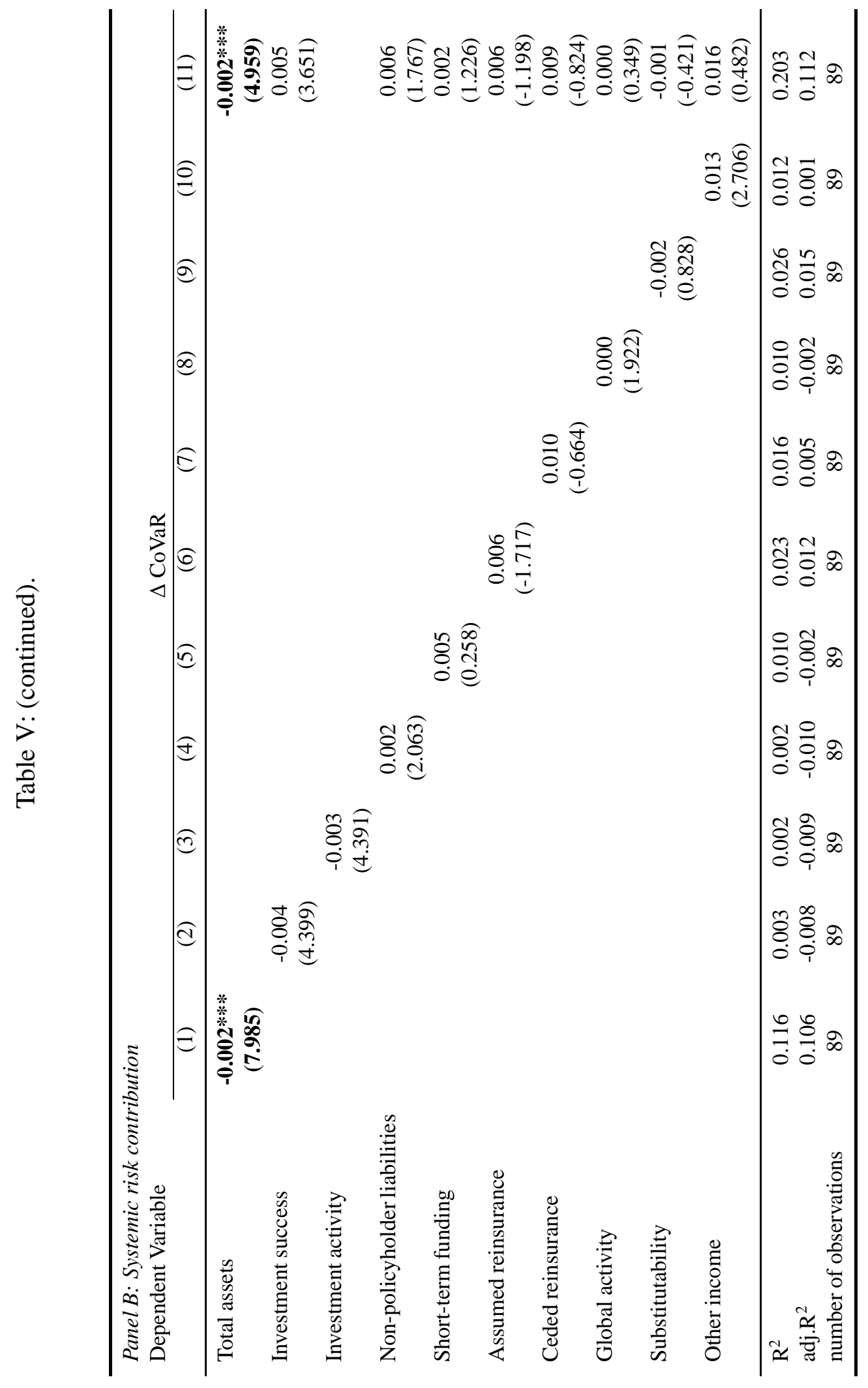


Table VI: Probit regressions predicting membership in the top MES quartile and TARP bailouts.

The table shows the marginal effects from probit regressions predicting whether an insurer's contribution to the overall systemic risk of the U.S. financial sector during the financial crisis, proxied by the insurer's Marginal Expected Shortfall, is in the top quartile, and whether an insurer received a bailout under the Troubled Assets Relief Program (TARP). Variable definitions and data sources are provided in Appendix [I] Numbers in parentheses are $z$-statistics. $* * *, * *, *$ denote coefficients that are significant at the $1 \%, 5 \%$, and $10 \%$ level, respectively.

\begin{tabular}{|c|c|c|c|c|c|c|c|c|c|}
\hline \multirow{2}{*}{ Dependent Variable } & \multicolumn{4}{|c|}{ Top MES quartile } & \multicolumn{5}{|c|}{ Insurer received TARP bailout } \\
\hline & (1) & (2) & (3) & (4) & (5) & (6) & (7) & $(8)$ & (9) \\
\hline Total assets & $\begin{array}{c}0.093 * * * \\
(3.882)\end{array}$ & & & $\begin{array}{l}0.070 * * \\
(2.506)\end{array}$ & $\begin{array}{c}0.044 * * * \\
(2.935)\end{array}$ & & & $\begin{array}{c}0.051 * * * \\
(2.675)\end{array}$ & $\begin{array}{l}\mathbf{0 . 0 5 8} * * \\
(2.222)\end{array}$ \\
\hline Investment success & & $\begin{array}{l}1.009 * * * \\
(3.459)\end{array}$ & & $\begin{array}{l}0.434 * \\
(1.663)\end{array}$ & & $\begin{array}{c}0.096 \\
(0.659)\end{array}$ & & $\begin{array}{c}-0.401 \\
(-1.366)\end{array}$ & $\begin{array}{r}-0.316 \\
(-0.901)\end{array}$ \\
\hline Non-policyholder liabilities & & & $\begin{array}{l}\mathbf{0 . 5 5 4} * * \\
(2.592)\end{array}$ & $\begin{array}{l}0.320 * \\
(1.804)\end{array}$ & & & $\begin{array}{l}0.239 * * \\
(2.193)\end{array}$ & $\begin{array}{c}0.192^{*} \\
(1.667)\end{array}$ & $\begin{array}{r}0.187 \\
(1.018)\end{array}$ \\
\hline Short-term funding & & & & $\begin{array}{c}0.236 \\
(1.418)\end{array}$ & & & & & $\begin{array}{l}-0.291 \\
(1.180)\end{array}$ \\
\hline Assumed reinsurance & & & & $\begin{array}{c}-0.240 \\
(-1.347)\end{array}$ & & & & & $\begin{array}{c}-0.129 \\
(-0.362)\end{array}$ \\
\hline Ceded reinsurance & & & & $\begin{array}{c}-0.058 \\
(-0.214)\end{array}$ & & & & & $\begin{array}{c}-0.213 \\
(-0.728)\end{array}$ \\
\hline Global activity & & & & $\begin{array}{c}-0.001 \\
(-0.585)\end{array}$ & & & & & $\begin{array}{l}-0.001 \\
(-0.892)\end{array}$ \\
\hline Substitutability & & & & $\begin{array}{l}-0.040 \\
(-1.027)\end{array}$ & & & & & $\begin{array}{c}0.024 \\
(0.737)\end{array}$ \\
\hline Other income & & & & $\begin{array}{c}0.234 \\
(0.593)\end{array}$ & & & & & $\begin{array}{c}-0.029 \\
(-0.109)\end{array}$ \\
\hline Asset Quality & & & & $\begin{array}{c}-0.800 \\
(-0.431)\end{array}$ & & & & & $\begin{array}{r}1.354 \\
(0.916)\end{array}$ \\
\hline Fixed Income & & & & $\begin{array}{c}0.199 \\
(0.570)\end{array}$ & & & & & $\begin{array}{c}0.074 \\
(0.362)\end{array}$ \\
\hline Market-to-book & & & & $\begin{array}{c}-0.065 \\
(-0.852)\end{array}$ & & & & & $\begin{array}{c}0.060 \\
(1.010)\end{array}$ \\
\hline $\begin{array}{l}\text { AIC } \\
\text { number of observations }\end{array}$ & $\begin{array}{c}86.980 \\
89\end{array}$ & $\begin{array}{c}88.930 \\
89\end{array}$ & $\begin{array}{c}97.997 \\
89\end{array}$ & $\begin{array}{c}89.058 \\
89\end{array}$ & $\begin{array}{c}34.825 \\
89\end{array}$ & $\begin{array}{c}47.581 \\
89\end{array}$ & $\begin{array}{c}43.186 \\
89\end{array}$ & $\begin{array}{c}35.262 \\
89\end{array}$ & $\begin{array}{c}46.888 \\
89\end{array}$ \\
\hline
\end{tabular}



